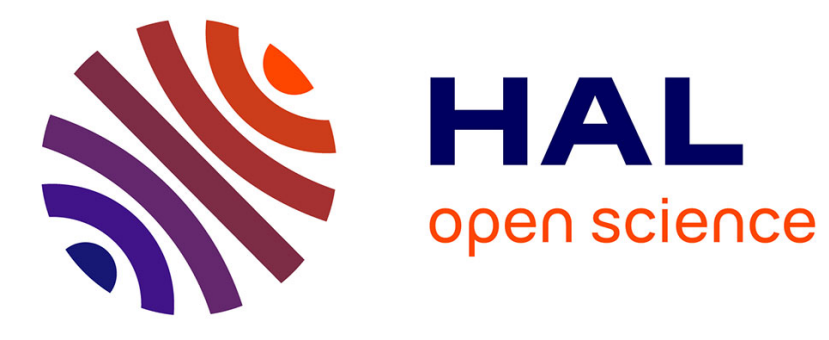

\title{
Hydration Properties and Interlayer Organization in Synthetic C-S-H
}

Stephane Gaboreau, Sylvain Grangeon, Francis Claret, Dris Ihiawakrim, Ovidiu Ersen, Valerie Montouillout, Nicolas Maubec, Cédric Roosz, Pierre Henocq, Cédric Carteret

\section{To cite this version:}

Stephane Gaboreau, Sylvain Grangeon, Francis Claret, Dris Ihiawakrim, Ovidiu Ersen, et al.. Hydration Properties and Interlayer Organization in Synthetic C-S-H. Langmuir, 2020, 36 (32), pp.94499464. 10.1021/acs.langmuir.0c01335 . hal-03003086

\section{HAL Id: hal-03003086 https://hal.science/hal-03003086}

Submitted on 2 Dec 2021

HAL is a multi-disciplinary open access archive for the deposit and dissemination of scientific research documents, whether they are published or not. The documents may come from teaching and research institutions in France or abroad, or from public or private research centers.
L'archive ouverte pluridisciplinaire HAL, est destinée au dépôt et à la diffusion de documents scientifiques de niveau recherche, publiés ou non, émanant des établissements d'enseignement et de recherche français ou étrangers, des laboratoires publics ou privés. 


\section{Hydration properties and interlayer organization in synthetic C-S-H.}

Gaboreau S. ${ }^{1 *}$, Grangeon S. ${ }^{1}$, Claret F. ${ }^{1}$, Ihiawakrim D. ${ }^{2}$, Ersen O. $^{2}$, Montouillout V. ${ }^{3}$, Maubec N. ${ }^{1}$, Roosz C. ${ }^{1}$, Henocq $P{ }^{4}{ }^{4}$, Carteret $C .{ }^{5}$

${ }^{1}$ BRGM, 3, avenue Claude Guillemin, F-45060 Orléans Cedex 2, France

${ }^{2}$ University of Strasbourg, CNRS, IPCMS, UMR 7504, 23 Rue du Loess, 67034 Strasbourg, France

${ }^{3}$ CNRS-CEMHTI UPR 3079, 1D Avenue de la Recherche Scientifique, 45071 Orléans, cedex 2 France

${ }^{4}$ Andra, 1/7 rue Jean Monnet, Parc de la Croix Blanche, 92298 Châtenay-Malabry Cedex, France

${ }^{5}$ LCPME, UMR 7564, CNRS-Université de Lorraine, 405 Rue de Vandoeuvre, 54600, Villers-les-Nancy, France

\section{Corresponding author : s.gaboreau@brgm.fr}

\section{Abstract}

Water in calcium silicate hydrate (C-S-H) is one of the key parameters driving the macroscopic behavior of cement materials, for which water vapor partial pressure has a impact on the Young's modulus and the volumic properties. Several samples of $\mathrm{C}-\mathrm{S}-\mathrm{H}$ with bulk $\mathrm{Ca} / \mathrm{Si}$ ratio ranging between 0.6 and 1.6 were characterized to study their dehydration/hydration behavior under water-controlled conditions, using ${ }^{29} \mathrm{Si}$ NMR, water adsorption volumetry, X-ray diffraction, and Fourier-transform near-infrared diffuse reflectance, under various water pressures. Coherent with several previous studies, it was observed that an increase in the $\mathrm{Ca} / \mathrm{Si}$ ratio is due to the progressive omission of Si bridging tetrahedra, with the resulting charge being compensated for by interlayer $\mathrm{Ca}$ and that water conditioning influences the layer-to-layer distance and the achieved NMR spectral resolution. Water desorption experiments exhibit one step toward low relative pressure, accompanied by a decrease in the layerto-layer distance. When sufficient energy is provided to the system ( $T \geq 40^{\circ} \mathrm{C}$ under vacuum) to remove the interlayer water, the shrinkage/swelling is partially reversible in our experimental conditions. A change in layer-to-layer distance of less than $3 \AA$ is measured in the C-S-H between the wet and dried states. When the bridging $\mathrm{SiO}_{2}$ tetrahedra are omitted, interlayer $\mathrm{Ca}$ interacts with layer $\mathrm{O}$ and water interacts with the cations and potentially with the surfaces. This structural organization is interpreted as a mid-plane monolayer of water in the interlayer space, this latter accounting for about $30 \%$ of the volume of C-S-H particles.

KEYWORDS: C-S-H, calcium silicate hydrates, water, interlayer space, hydration properties, porosity 


\section{Introduction}

Nanocrystalline Calcium Silicate Hydrate ( $\mathrm{C}-\mathrm{S}-\mathrm{H})$ is the main product that forms upon the reaction of cement with water. It has been extensively studied to understand it structure ${ }^{1-2}$, kinetics and mechanisms of precipitation ${ }^{3}$ and dissolution ${ }^{4}$, and its role in the hardening of hydrated cement materials $s^{5-7}$.

Different experimental and computational models have been proposed to describe the structure of C$\mathrm{S}-\mathrm{H}$ based for example on thermodynamic calculation ${ }^{8-9}$, molecular dynamic simulations ${ }^{10-11}$, crystallographic characterization ${ }^{1,12-14}$ or gas adsorption ${ }^{15-18}$. Collectively, these studies did not only allow a better understanding of the $\mathrm{C}-\mathrm{S}-\mathrm{H}$ structure and size, but also of water distribution, and the mechanisms of interactions between various ions and C-S-H surfaces. Furthermore, the role of the interactions at the molecular scale on the macroscopic behavior of hydrated cement materials has been highlighted.

The structure of C-S-H consists in the parallel stacking of layers built of two $\mathrm{SiO}_{2}$ layers sandwiching a $\mathrm{Ca}$ layer, with $\mathrm{Ca}$ being 7 -fold coordinated to $\mathrm{O} / \mathrm{H}_{2} \mathrm{O}$. The presence of $\mathrm{Si}$ vacancies in the $\mathrm{SiO}_{2}$ layers creates a layer charge that is compensated by $\mathrm{Ca}{ }^{2,11,19-20}$. The number of $\mathrm{Si}$ vacancies varies as a function of the synthesis method and the ratio of $\mathrm{Ca}$ and $\mathrm{Si}$ used for synthesizing $\mathrm{C}-\mathrm{S}-\mathrm{H}$, the resulting $\mathrm{C}-\mathrm{S}-\mathrm{H}$ thus has a variable charge and crystal chemistry, generally referred to through the macroscopic calcium to silicon $(\mathrm{Ca} / \mathrm{Si})$ ratio. $\mathrm{C}-\mathrm{S}-\mathrm{H}$ thus shares many structural similarities with tobermorite, the main difference being that C-S-H is nanosized and has turbostratic stacking ${ }^{21}$. In addition, the size of the crystallite perpendicular to the layer plane (i.e., the mean number of layers stacked coherently) depends on the $\mathrm{Ca} / \mathrm{Si}$ ratio ${ }^{13,17}$.

The presence of undersaturated oxygen atoms at the layer edges and the external basal surfaces and the resulting interparticle interactions is one of the explanations of the cohesive properties of hydrated cement, and control the interactions with positively charged ions and molecules ${ }^{11,22-23}$. In addition, Bonnaud, et al. ${ }^{24,25}$, through molecular dynamic simulation, also demonstrated the role of confined water in C-S-H micropores on the cohesion of cement paste. Thus, it is expected that the properties of $\mathrm{C}-\mathrm{S}-\mathrm{H}$, and more generally of many cements, will show dependency on the $\mathrm{Ca} / \mathrm{Si}$ ratio.

Despite the large number of previous studies on C-S-H structure, a full description of interlayer Ca and water distribution as a function of the $\mathrm{Ca} / \mathrm{Si}$ ratio is still lacking. Such knowledge is however important to the understanding of interparticular electrostatic interactions ${ }^{26}$. Richardson ${ }^{1}$ and Grangeon, et al. ${ }^{21}$ showed that the layer-to-layer distance, designated $d_{001}$ hereafter, depends on the $\mathrm{Ca} / \mathrm{Si}$ ratio. In addition, this layer-to-layer distance also changes with water content ${ }^{17,27-28}$. In this regard, Roosz, et al. ${ }^{17}$ showed that relative humidity $(\mathrm{RH})$ and drying conditions must be controlled to obtain $\mathrm{C}-\mathrm{S}$-H data that can be linked to the environmental parameters (in particular the quantity of water in the system), and compared to data from other studies, thus ultimately offering robust insights into C-S-H. However, for $\mathrm{C}-\mathrm{S}-\mathrm{H}$, the notion of stepwise reversible hydration, that has long been demonstrated for swelling clay minerals, remains debated ${ }^{29}$ even although an analogy with the behavior of tobermorite, which exhibits phases at 14, 11 and $9 \AA$ 象ith decreasing water content has been shown for C-S-H $\mathrm{H}^{21}$.

The present paper aims at providing information on the hydration properties and interlayer organization of the $\mathrm{C}-\mathrm{S}-\mathrm{H}$ structure with different $\mathrm{Ca} / \mathrm{Si}$ ratios by combining solid state Nuclear Magnetic Resonance (NMR) measurements, water adsorption experiments, powder X-Ray Diffraction (XRD) and infra red (IR) measurements under controlled water pressure and in situ liquid transmission 
electron microscopy (TEM). We analyzed the structure of these materials for various relative humidity and drying conditions in order to provide new insight into their structural properties and knowledge of the chemical and mechanical behavior of such cement-based materials. To go a step further in our interpretation and its comparison to existing literature, a particular care has been taken in the sample conditioning and its impact on the probed signal.

\section{Materials and Methods}

Synthesis of samples

All C-S-H samples were prepared in a $\mathrm{N}_{2}$ glove box by mixing calcium hydroxide $\left[\mathrm{Ca}(\mathrm{OH})_{2}-\right.$ Prolabo] heated at $1000{ }^{\circ} \mathrm{C}$ for 24 hours and amorphous silica ( $\mathrm{SiO}_{2}$ - Aerosil 200, Degussa). Ultrapure water (resistivity $=18 \mathrm{M} \Omega \cdot \mathrm{cm}$ ), was boiled and outgassed under a $\mathrm{N}_{2}$ flow prior to being introduced into the glovebox.

C-S-H samples, with target $\mathrm{Ca} / \mathrm{Si}$ ratios ranging from 0.6 to 1.6 , were synthesized using a precipitation method at $22{ }^{\circ} \mathrm{C}$. In what follows, these samples are labeled C-S-H X, where X stands for the target $\mathrm{Ca} / \mathrm{Si}$ ratio. The homogenized reactants were mixed with distilled, $\mathrm{CO}_{2}$-free water at a water/solid ratio of 50. Each synthesis tube was shaken in tightly closed PE-vessels for one month at $22{ }^{\circ} \mathrm{C}$ and stored for one year in the $\mathrm{N}_{2}$ glovebox. After one year, the samples were filtered (cut-off diameter of $0.22 \mu \mathrm{m}$ Millipore, using Millex-VV, PVDF filters). The C-S-H gel was pressed between paper filters and stored in the $\mathrm{N}_{2}$ glovebox at a relative humidity of $\sim 80 \%$.

The chemical composition of C-S-H was assessed both by Electron Probe Micro Analysis (EPMA) and from the difference between the initial and final amounts of $\mathrm{Ca}$ and $\mathrm{Si}$ in solid and in solution ${ }^{30}$. As shown in Table 1, both gave similar results.

Table 1 Chemical composition of the synthesized C-S-H. Note: the uncertainties are the standard error calculated from 20 independent measurements

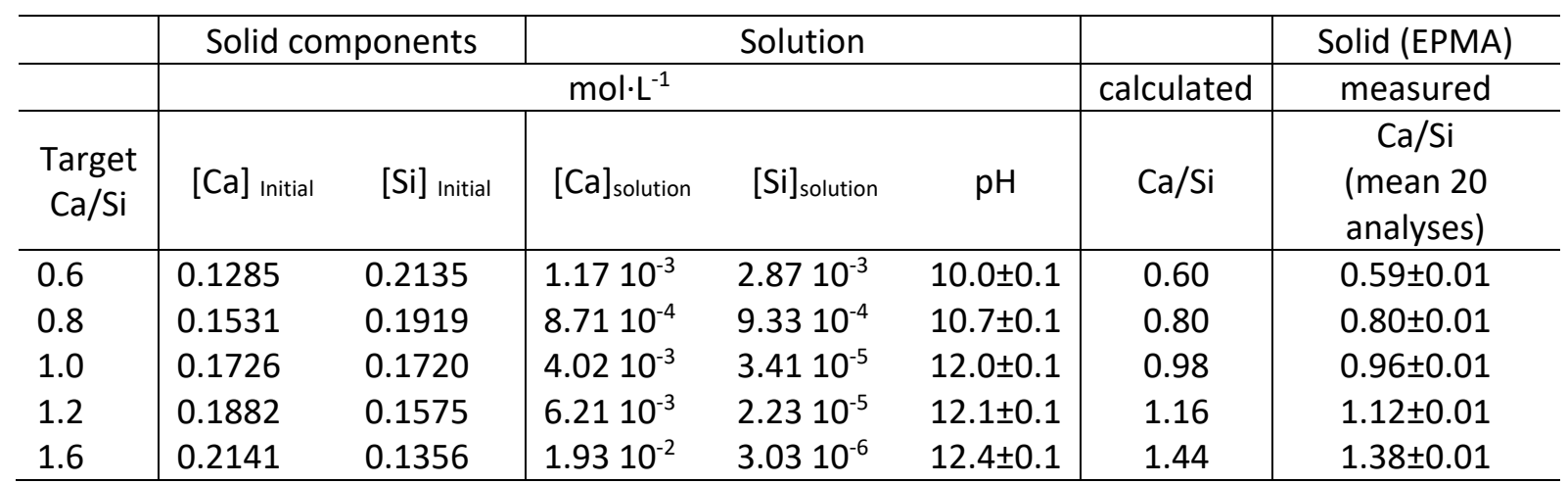

\section{Sample characterization}

NMR. ${ }^{29} \mathrm{Si}$ NMR spectra were recorded on a Bruker AVANCE 9.3 T operating at $79.5 \mathrm{MHz}$ and equipped with a $4 \mathrm{~mm}$ double bearing MAS probe head spinning at $12 \mathrm{kHz}$. About 16000 scans were accumulated after a $45^{\circ}$ pulse, using a $60 \mathrm{~s}$ recycling delay. This delay was optimized to ensure the complete relaxation of the magnetization. ${ }^{29} \mathrm{Si}$ chemical shifts are reported relative to tetramethylsilane resonance. The spectra were simulated as a sum of individual Gaussian-Lorentzian functions, using the Dmfit software ${ }^{31}$. Their integrated intensities were used to estimate the amount of the differently coordinated species. The mean Si chain length (i.e. the mean number of Si atoms that are connected 
in a tetrahedral layer) was calculated following Richardson ${ }^{1}$. All measurements were performed on samples equilibrated at $60 \% \mathrm{RH}$.

Water vapor adsorption volumetry. Water vapor adsorption-desorption isotherms at $25{ }^{\circ} \mathrm{C}$ were obtained using a MicrotracBEL Belsorp-Max volumetric adsorption analyzer equipped with three pressure sensors ( $133 \mathrm{kPa}, 1.33 \mathrm{kPa}$ and $13.3 \mathrm{~Pa}$ ). Long acquisition times ( $\approx 7$ days per isotherm) were required due to slow equilibrium kinetics. Isotherms were acquired for $\mathrm{C}-\mathrm{S}-\mathrm{H}$ 0.8, 1.0, 1.2 and 1.6. All investigated samples were outgassed at $40{ }^{\circ} \mathrm{C}$ under vacuum under a residual pressure of $310^{-6} \mathrm{~Pa}$. The isotherms were compared to $t$ standard curves obtained from data on a series of nonporous or macroporous adsorbents ${ }^{32}$ with energetic BET $C$ constants similar to those of our samples. The $t$-plot method ${ }^{33}$ was used to redraw the standard multilayer thickness on the reference nonporous material at the corresponding $\mathrm{P} / \mathrm{P}_{0}$, in the absence of capillary condensation. The same formalism of calculation was already applied on C-S-H samples ${ }^{17}$. The $t$ method allows the micropore volume, total surface area and non-microporous surface area to be determined.

NIR-DR. Near-infrared diffuse reflectance spectra under controlled water pressure were recorded on a Nicolet 8700 Fourier Transform InfraRed (FTIR) spectrometer, equipped with a MCT detector. The spectra in diffuse reflectance mode were collected using an environmental cell with a Harrick Praying Mantis $^{\mathrm{TM}}$. The near-infrared region (i) makes it possible to work on pure mineral powders, and (ii) provides quantitative data on water content in the samples. More detailed technical information can be found in Rinnert, et al. ${ }^{34}$. A humid atmosphere with controlled RH was generated using an in-house dynamic system mixing a dry and a wet $\mathrm{N}_{2}$ flow, controlled by a mass flow meter. Using such a set-up, a RH between 0 and $100 \%$ can be generated with an uncertainty of 0.3-0.5\%. All samples were analyzed first in desorption starting from a water-saturated state close to $90 \%$. RH was then reduced step by step before drying at 40 and $100{ }^{\circ} \mathrm{C}$ under vacuum. Data on the adsorption branch were then acquired by increasing $\mathrm{RH}$. For each $\mathrm{RH}$ value, equilibrium was checked by recording the evolution of spectra over time. The time required to reach equilibrium ranged between 30 minutes and 1 hour, depending on water pressure. The reproducibility of the experiments was checked by carrying out two water adsorption-desorption isotherms for each sample. The spectrum resolution was $4 \mathrm{~cm}^{-1}$. Diffuse reflectance spectra were recorded from 9000 to $3000 \mathrm{~cm}^{-1}$. Three individual scans were summed to increase the signal-to-noise ratio. Ground potassium bromide powder dried under vacuum $\left(10^{-3} \mathrm{~Pa}\right)$ at $30{ }^{\circ} \mathrm{C}$ was used as a reference ( $R 0$ signal). The reflectance spectra are displayed in $-\log (R / R 0)$, where $R$ corresponds to the diffuse reflection collected for the sample.

In situ scanning transmission electron microscopy (STEM). For in situ STEM investigation, a droplet of synthesis solution containing C-S-H particles was deposited on a specific chip. An atmosphere gas cell system allowed sample exposure under a water-saturated atmosphere. TEM images were recorded on a JEOL 2100F (FEG) TEM/STEM electron microscope operating at $200 \mathrm{KV}$ equipped with a spherical aberration and an Ultra scan 1000 CCD array detector. The high-angle annular dark field (HAADF) and bright field (BF) images of the chosen areas were recorded simultaneously.

Temperature and water pressure controlled XRD. X-ray diffraction was performed using a Bruker D8 Advance Da Vinci diffractometer equipped with $\mathrm{CuK}_{\alpha}$ radiation $(\lambda=1.5418 \AA$ ) operating at $40 \mathrm{kV}$ and $40 \mathrm{~mA}$ and a LynXeye XE 1D Detector. For temperature experiments, samples were measured at temperatures ranging from $25{ }^{\circ} \mathrm{C}$ to $900{ }^{\circ} \mathrm{C}$ using an XRK900 reaction chamber (Anton Paar GmbH, Graz, Austria). Data were collected over the $4-40^{\circ} 2 \theta$ Cuk $\alpha$ angular range and averaged every $0.03^{\circ} 2 \theta$. 
XRD patterns were acquired from wet samples equilibrated at $90 \% \mathrm{RH}$ and increasing temperature up to $900{ }^{\circ} \mathrm{C}$. For each temperature step, XRD patterns were collected after 1 hour or more of heating.

For the humidity experiments, a Modular Humidity Generator (MHG) produced by Projekt Messtechnik coupled to an Anton Paar $\mathrm{CHC}+$ chamber was used. Samples were measured over the 4-35 ${ }^{\circ} 2 \theta$ CuK $\alpha$ angular range and data were averaged every $0.03^{\circ} 2 \theta$. After being introduced into the $\mathrm{CHC}+$ chamber, samples were equilibrated at the desired $\mathrm{RH}$ for 30 or 60 minutes at $25^{\circ} \mathrm{C}$, and were then analyzed by maintaining these $(\mathrm{T}, \mathrm{RH})$ conditions. $\mathrm{RH}$ was controlled with a hygrometer located close to the sample. All acquisitions were performed starting from a water-saturated state close to $90 \% \mathrm{RH}$. Different desorption/adsorption cycles were implemented step by step. The dry state analysis was performed by outgassing the chambers $\left(\approx 5.10^{-2} \mathrm{mbar}\right)$ at $40^{\circ} \mathrm{C}$ or $100^{\circ} \mathrm{C}$. The adsorption branch was acquired after total dehydration at $100{ }^{\circ} \mathrm{C}$ under vacuum.

XRD patterns were recorded with divergence slits of 0.6 and 0.1 for temperature and RH conditions, respectively. Data from both datasets can thus not be strictly compared, in particular in the low-angle part of the XRD patterns.

Modeling of XRD patterns. All XRD calculations were performed using software developed by Plançon 35, 36, based on the mathematical formalism developed by Drits and Tchoubar ${ }^{37}$ and already successfully applied to C-S-H for modeling both hk bands and $00 /$ reflections ${ }^{12,21}$. Here $00 /$ reflections were modeled assuming that the interstratification of several different interlayers could occur (yet was only considered when pure phases could not straightforwardly explain the pattern). Briefly, interstratification is defined as the stacking, perpendicular to the layer plane, of at least two types of "layers" (composed of both the strictly speaking Ca-Si layer itself and an interlayer space) of contrasting chemical or structural composition. A definition of the Markovian statistics used here to describe the probability that a given layer type follows another layer type (including the Reichweite parameters) can be found in Drits and Tchoubar ${ }^{37}$. Briefly if $R=0$, then the composition of a given interlayer does not depend on the composition of the other interlayers in a given crystal. If $R=1$, then the composition of a given interlayer depends on that of the previous interlayer. The crystallographic parameters of the layers defined for modeling purposes are given in Table 3 . Three different components were used. Their respective layer-to-layer distances were 9.6, 12 and $13.9 \AA$, as constrained by STEM measurements. It is noteworthy that the lack of a well-defined series of 00 I reflections induces significant uncertainties in our analysis, including in the accurate quantification of the layer-to-layer distance, of the interstratification parameters, and of the relative proportions of each type of layer. These uncertainties are magnified by the fact that a multi-specimen approach ${ }^{38}$ was not conducted. This, for example, means that the assumed $12 \AA$ layer-to-layer distance could indeed be equal to $11.3 \AA$, in dry state, a value that was previously observed for tobermorite ${ }^{28}$, the crystalline and natural analog of C-S-H. The same uncertainties also apply to an accurate quantification of the junction parameters and to the quantity of each individual component of the interstratified phase. Overall, this modeling exercise has to be considered to be subject to strong uncertainties.

TGA. Thermogravimetric analysis was performed on a TGA-differential thermal analysis (DTA) instrument (Setaram SETSYS Evolution) using 200-300 mg of each sample. Acquisitions were performed on fully hydrated samples, equilibrated at different $\mathrm{RH}$. The samples were heated from room temperature to $1000{ }^{\circ} \mathrm{C}$ with a heating rate either of $10^{\circ} \mathrm{C} / \mathrm{min}$ or with plateaus of several hours at 150,700 , and $1000^{\circ} \mathrm{C}$. 


\section{Results}

NMR. Figure 1 shows ${ }^{29} \mathrm{Si} \mathrm{NMR} \mathrm{spectra} \mathrm{of} \mathrm{C}-\mathrm{S}-\mathrm{H}$ with $\mathrm{Ca} / \mathrm{Si}$ ratios ranging between 0.6 and 1.6 and of amorphous silica used in the synthesis, conditioned at $60 \% \mathrm{RH}$. It is worth noting that the spectral resolution in wet condition is higher than in dry condition as exemplified with the $\mathrm{Ca} / \mathrm{Si}$ ratio of 0.6 (Figure 1; higher ratio not shown). The main resonances at $-79.5,-83$ and $-85 /-85.5 \mathrm{ppm}$ are assigned to $Q_{1}$ and $Q_{2}$ species in C-S-H, in agreement with literature data ${ }^{39}$. In the case of C-S-H 0.6 , an additional $\mathrm{Q}_{3}$ resonance is detected at around $-95 \mathrm{ppm}$. This broad contribution that accounts for almost $30 \%$ of the total $\mathrm{Si}$ is markedly different from the narrow signals corresponding to $Q_{1}$ and $Q_{2}$ sites. It is assigned to residual products from the amorphous silica used in the synthesis, although some authors have attributed this broader contribution to $\mathrm{C}-\mathrm{S}-\mathrm{H} \mathrm{Q}_{3}{ }^{19}$. In the range corresponding to $Q_{1}$ and $\mathrm{Q}_{2}$ sites, the fitting of the spectra involves more than three components as shown in previous works ${ }^{40}$. In particular, several contributions are needed to reproduce the $Q_{2}$ peak at $-85 /-85.5 \mathrm{ppm}$ (Figure 1B). In the following, all $\mathrm{Q}_{2}$ contributions will be summed and only the behavior of this sum as a function of the $\mathrm{Ca} / \mathrm{Si}$ will be discussed. As observed in previous literature studies ${ }^{19,40}$ and in Figure $1 \mathrm{~A}$ and Figure $1 \mathrm{C}$, ${ }^{29} \mathrm{Si} \mathrm{NMR} \mathrm{spectra} \mathrm{significantly} \mathrm{evolve} \mathrm{as} \mathrm{a} \mathrm{function} \mathrm{of} \mathrm{the} \mathrm{Ca} / \mathrm{Si}$ ratio. With increasing $\mathrm{Ca} / \mathrm{Si}$, the intensity of the $Q_{1}$ peak increases whereas that of the $Q_{2}$ signal decreases. The intensity of the signal located between these two components, at $-83.1 \mathrm{ppm}$, assigned to bridging tetrahedra $\left(\mathrm{Q}_{2 \mathrm{~b}}\right)$ in the Dreierketten chains of tobermorite-like silicates, also decreases with increasing $\mathrm{Ca} / \mathrm{Si}$. The evolution of peak intensity is summarized in Figure $1 \mathrm{C}$. As previously observed by Klur, et al. ${ }^{40}$, the intensity of the $\mathrm{Q}_{1}$ signal markedly increases when the $\mathrm{Ca} / \mathrm{Si}$ ratio rises from 0.8 to 1.0 , concomitantly with a significant broadening of this contribution. The proportions of $Q_{1}$ and $Q_{2}$ sites are used to calculate the mean silicate chain length (mean number of Si atoms connected along the Dreierketten chains) and the mean number of Si vacancies, following Richardson ${ }^{1}$.
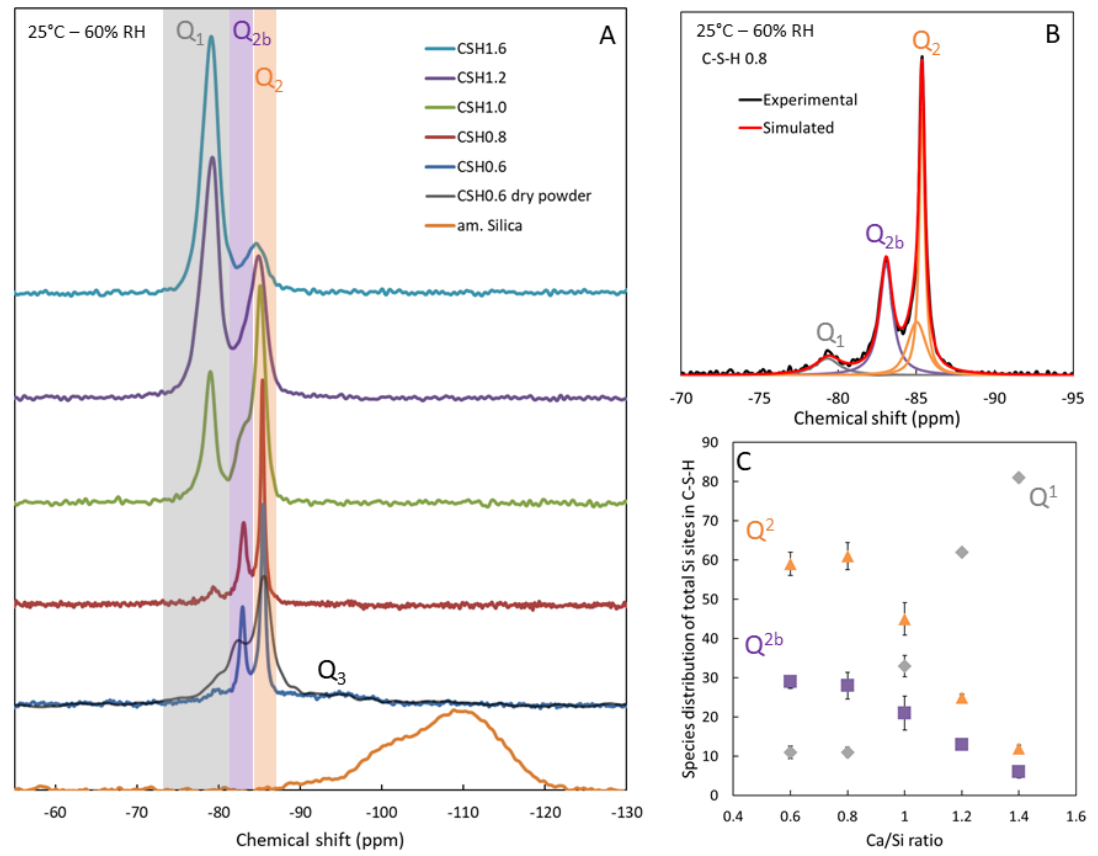

Figure $1{ }^{29} \mathrm{Si} \mathrm{NMR}$ spectra acquired on $\mathrm{C}-\mathrm{S}-\mathrm{H}$ samples synthesized at $25^{\circ} \mathrm{C}$ and equilibrated at $60 \%$ relative humidity. (A) The spectra are arranged from top to bottom by decreasing $\mathrm{Ca} / \mathrm{Si}$, the spectrum of the amorphous silica used in the synthesis is also included. The colored areas indicate the main Si 
sites, $Q_{1}, Q_{2 b}$ and $Q_{2}$. (B) Example of decomposition of spectra. (C) Evolution of the proportion of Si sites as a function of $\mathrm{Ca} / \mathrm{Si}$ ratio. For the 0.6 ratio measurements in both wet and dry condition are given.

Table 1 displays the abundance of the three main resonances deduced from the quantitative treatment of the spectra and the corresponding mean chain length and proportion of vacant tetrahedral sites calculated according to the formalism given in Richardson ${ }^{1}$. In agreement with previous studies ${ }^{1,30}$, the mean chain length decreases with the increase of $\mathrm{Ca} / \mathrm{Si}$ ratio and shows a significant drop between 0.8 and 1.0. Mechanically, the amount of vacant tetrahedral sites $(v)$ increases and plateaus at a value close to $1 / 3$ for a $\mathrm{Ca} / \mathrm{Si}$ ratio of 1.6 , coherent with several previous observations ${ }^{1,13,19,41}$. We note that the absolute values of the mean chain length and of $v$ also concur with these previous studies, and that the 0.05 vacancy per $\mathrm{Si}$ site for the sample with a $\mathrm{Ca} / \mathrm{Si}$ ratio of 0.6 is certainly due to the Si chain truncation effect ${ }^{42}$.

Table 2 Relative abundance of Si sites in C-S-H calculated from the decomposition of 29Si MAS NMR spectra, as well as mean chain length and vacant tetrahedral sites ( $v$ ).

\begin{tabular}{cccccc}
\hline \multicolumn{7}{c}{$\begin{array}{c}\text { Relative abundance } \\
\text { of Si sites (\%) }\end{array}$} & $\begin{array}{c}\text { Mean chain } \\
\text { length }\end{array}$ & $\begin{array}{c}\text { Vacant } \\
\text { tetrahedral } \\
\text { sites (v) }\end{array}$ \\
\hline Sample & $Q^{1}$ & $Q^{2 b}$ & $Q^{2}$ & & \\
C-S-H 0.6 & 11 & 29 & 60 & 18 & 0.05 \\
C-S-H 0.8 & 11 & 28 & 61 & 18 & 0.05 \\
C-S-H 1.0 & 33 & 21 & 46 & 6 & 0.14 \\
C-S-H 1.2 & 62 & 13 & 25 & 3.2 & 0.23 \\
C-S-H 1.6 & 81 & 6 & 12 & 2.4 & 0.29 \\
\hline
\end{tabular}

In situ TEM acquisition. STEM images were collected for C-S-H 0.8, 1.0 and 1.2 under a water-saturated atmosphere. The samples could thus be observed in a hydrated state and are not dehydrated due their observation in vacuum which generally occurs during a classical TEM analysis. In the case of C-S-H 0.8, significant beam damage is observed. The beam damage effect is apparently less prominent for $\mathrm{C}-\mathrm{S}-\mathrm{H}$ 1.0 and 1.2 (Figure 2) for which images are acquired. From a Fast Fourier Transform of the images, the $\mathrm{C}$-S-H layer-to-layer distance is quantified. For C-S-H 1.0, two distances are measured. Some particles of 3 to 6 layers display a distance of $14 \AA$, while other particles display stacks at $14 \AA$ associated with stacks at $12.2 \AA$ (Figure 2). In the case of C-S-H 1.2, particle stacks of 4 to 8 layers are observed with a constant mean layer-to-layer distance measured at $12.3 \AA$. 

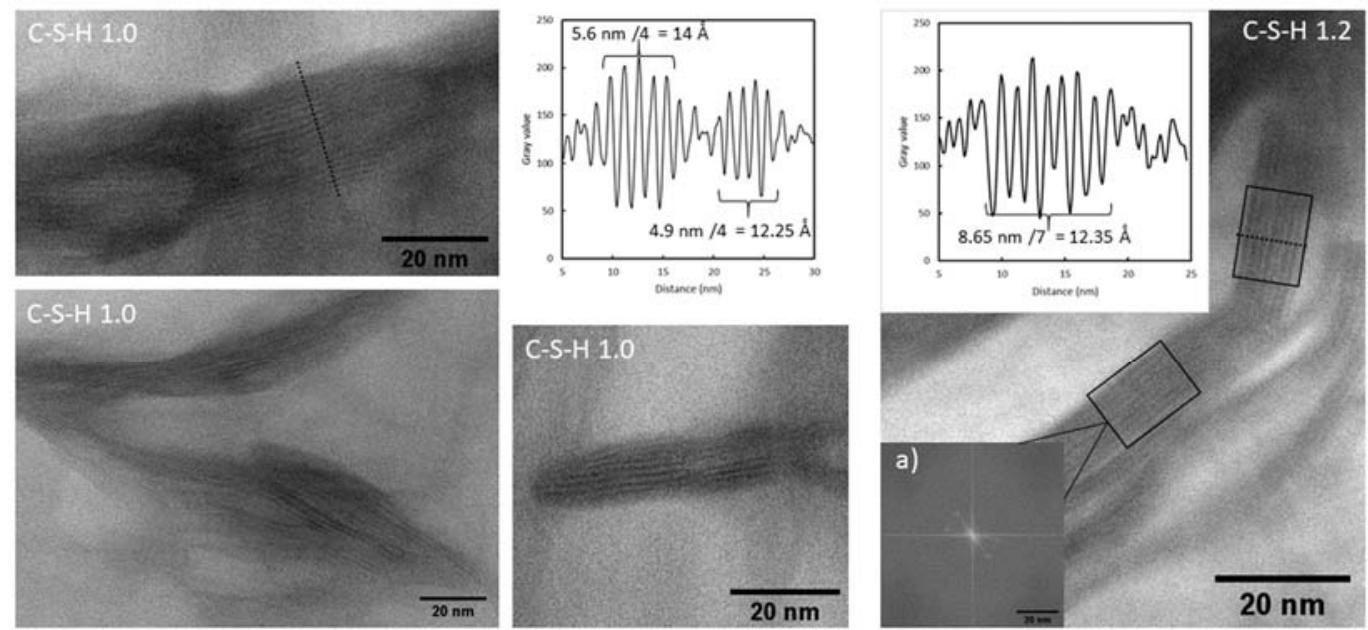

Figure 2 In situ STEM bright field images of C-S-H1.0 and 1.2. The graphs highlight the layer-to-layer distance measured along the dotted lines. Inset a) : Fast Fourier Transform of the areas denoted with black rectangles.

Temperature and water pressure controlled XRD. Figure 3Figure 4Figure 5Figure 6 display the XRD patterns of C-S-H 0.8, 1.0, 1.2 and 1.6, respectively, as a function of temperature and/or relative humidity. The patterns are typical for $\mathrm{C}-\mathrm{S}-\mathrm{H}$, with broad and, for some of them, asymmetric peaks assignable to $(00 /)$ and $\mathrm{hk}$ bands ${ }^{12,}{ }^{21}$. As the $\mathrm{Ca} / \mathrm{Si}$ ratio increases, the intensity of the band at $\sim 15.6$ ${ }^{\circ} 2 \theta$ decreases relative to that at $\sim 29.1^{\circ} 2 \theta$, which is consistent with previous observations ${ }^{13}$. Changes in temperature and relative humidity lead to pronounced variations both in position and intensity of the $00 /$ reflections whereas $h k$ bands are, as expected, less affected. For all samples, the 001 reflection shifts towards high diffraction angles (low $d$-spacing) with increasing temperature while the effect of $\mathrm{RH}$ varies with the $\mathrm{Ca} / \mathrm{Si}$ ratio. For samples with a target $\mathrm{Ca} / \mathrm{Si}$ ratio of 0.8 (Figure 3), upon heating up to $150{ }^{\circ} \mathrm{C}$, the position of the 001 reflection evolves from $14.2 \pm 0.3 \AA$ to $11.6 \pm 0.3 \AA$. In parallel the intensity of the peak decreases while its width increases. Note that the $h k$ bands shift towards low $d$ spacing values when temperature increases above $60^{\circ} \mathrm{C}$, in dicative of a change in $\mathrm{C}-\mathrm{S}-\mathrm{H}$ layer structure. XRD patterns recorded under controlled water pressure conditions are not shown because the 001 was too poorly defined. 


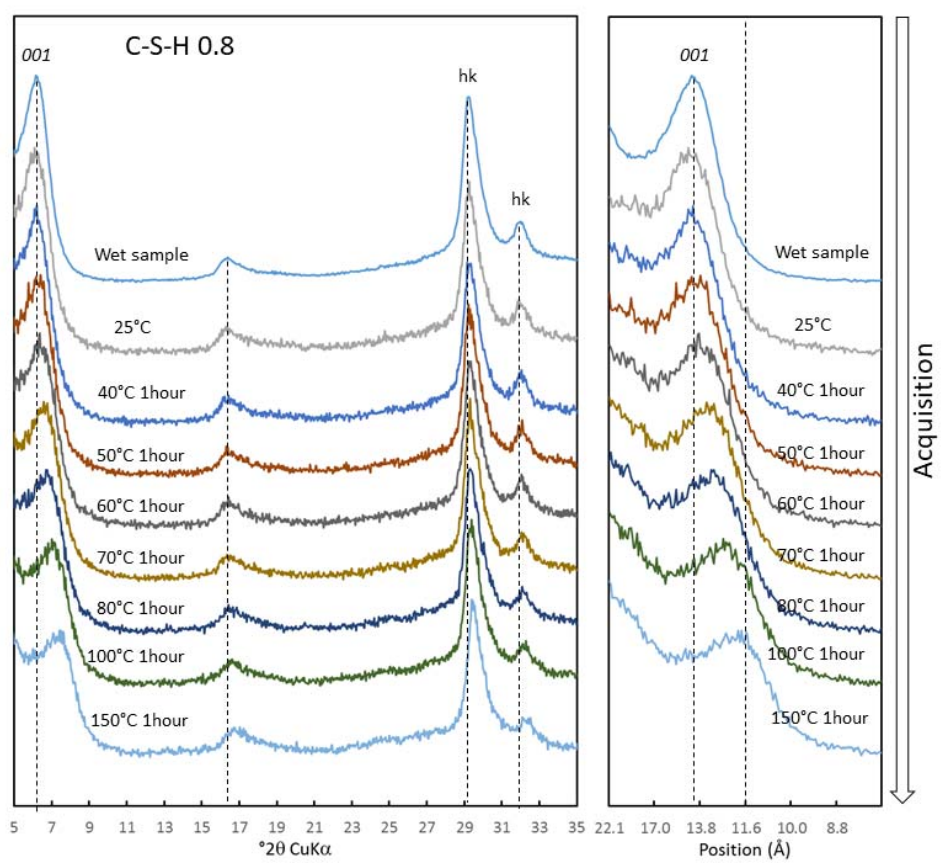

Figure 3 Experimental XRD patterns of C-S-H 0.8 as a function of temperature.

For C-S-H 1.0 (Figure 4), temperature and RH also affect the position and intensity of the 001 reflection. The wet sample as well as the sample equilibrated at $90 \%$ RH have a 001 reflection positioned at 13.7 $\pm 0.3 \AA$, whereas it shifts to $10.4 \pm 0.3 \AA$ for the sample conditioned at $150^{\circ} \mathrm{C}$ as well as that conditioned at $25^{\circ} \mathrm{C}$ under vacuum. In comparison with what is observed for C-S-H 0.8 , the 001 exhibits a significant asymmetry on its high angle side, indicative of interstratification or the presence of two or more distinct layer-to-layer distances in different crystal populations. The $h k$ bands also shift toward low $d$ spacing values for temperatures higher than $60^{\circ} \mathrm{C}$, evidencing a change in layer structure. XRD patterns obtained for various $\mathrm{RH}$ values with various dehydration/rehydration cycles (Figure 4) reveal almost fully reversible changes when the $\mathrm{RH}$ decreases to $30 \%$ before rehydration, whereas lower $\mathrm{RH}$ values in desorption lead to only partial rehydration. Indeed, when the sample is dehydrated to $5 \% \mathrm{RH}$, the 001 reflection is positioned at $11.4 \pm 0.3 \AA$ and upon rehydration, the position of this maximum is at $12.2 \pm 0.3 \AA$. We note however that these positions cannot strictly be related to a layer-to-layer distance, due to both C-S-H nanocrystallinity and possible interstratification. This will be discussed below. When the sample is then conditioned at $25^{\circ} \mathrm{C}$ under vacuum, the (001) position is located at $10.4 \pm 0.3 \AA$, i.e., the same position as at $150^{\circ} \mathrm{C}$. Rehydration is far from complete as a position of 11.9 $\pm 0.3 \AA$ is reached after one hour of equilibrium. Longer hydration times up to 4 hours do not have any effect on this latter value. 

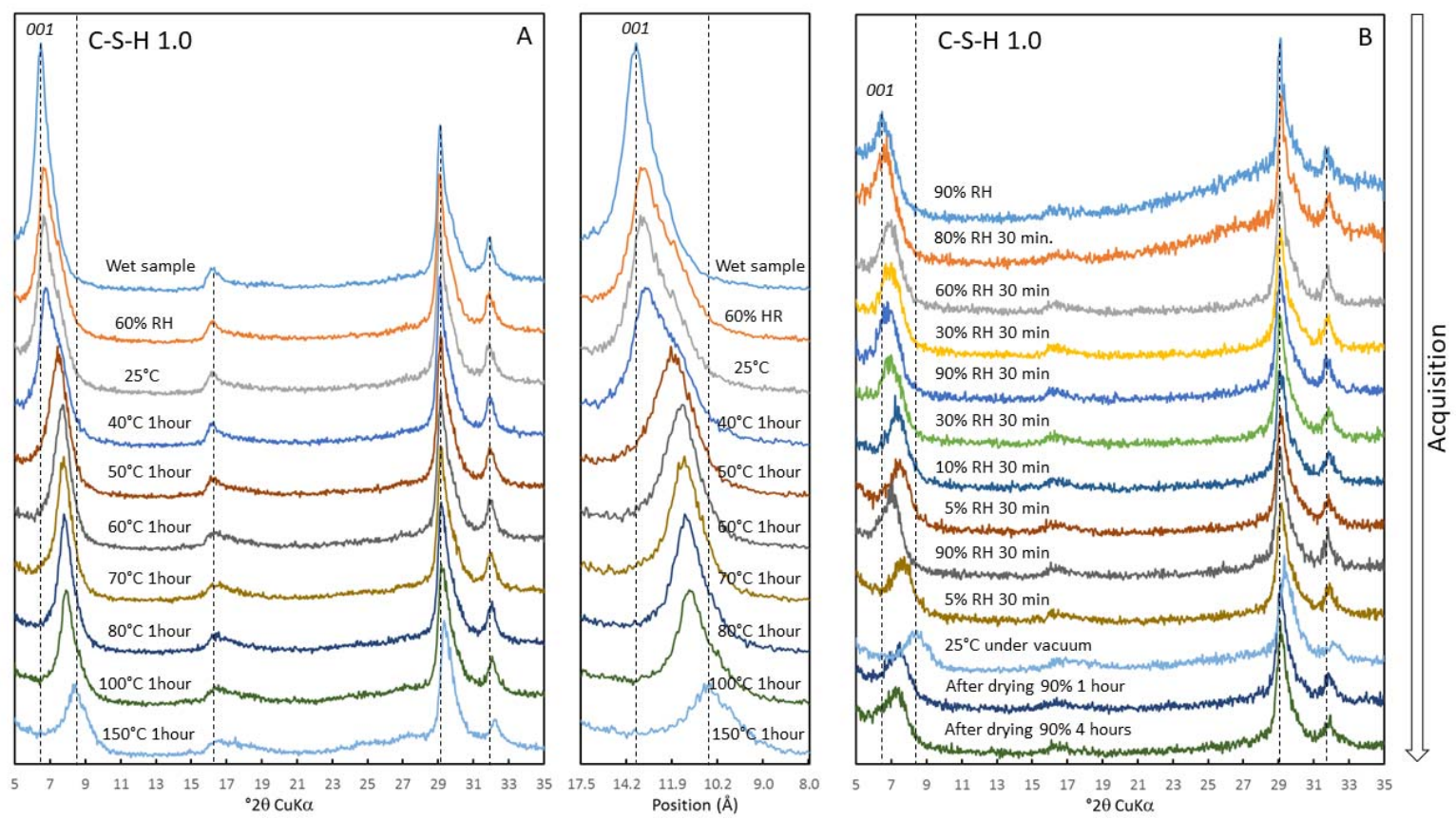

Figure 4 Experimental XRD patterns of $\mathrm{C}-\mathrm{S}-\mathrm{H} 1.0$ as a function of temperature $(A)$ and of relative humidity (B).

For C-S-H 1.2 (Figure 5), as for the two previous samples, temperature and $\mathrm{RH}$ affect the position and intensity of the signal corresponding to the 001 reflection, which in this case is located at $7.2-9.3^{\circ} 2 \theta$. The 001 reflection of the wet sample and of the sample equilibrated at $90 \% \mathrm{RH}$ is positioned at $12.3 \pm$ $0.3 \AA$ and shifts to $9.4 \pm 0.3 \AA$ for the sample conditioned at $150^{\circ} \mathrm{C}$ as well as that conditioned at $25^{\circ} \mathrm{C}$ under vacuum. Unlike the two other samples, evidence for a change in layer structure is only observed at temperatures higher than $100^{\circ} \mathrm{C}$, for which the $h k$ bands shift towards the low $d$-spacing values. XRD patterns obtained for various $\mathrm{RH}$ values with various dehydration/rehydration cycles (Figure 4B) exhibit similar trends to that observed for the other samples. Indeed, when the RH decreases down to $30 \%$, the position of the 001 reflection shifts to $11.7 \pm 0.3 \AA$, and returns to $12.1 \pm 0.3 \AA$ upon rehydration at $90 \% \mathrm{RH}$ close to the initial position ( $12.3 \pm 0.3 \AA$ ). Dehydration down to $5 \% \mathrm{RH}$ leads to a position at the 001 reflection of $11.3 \pm 0.3 \AA$ and upon rehydration, it returns to $12.1 \pm 0.3 \AA$. When the sample is then conditioned at $25{ }^{\circ} \mathrm{C}$ under vacuum, the (001) position is at $9.4 \pm 0.3 \AA$, similar to what was observed when the sample was heated to $150^{\circ} \mathrm{C}$. Rehydration upon exposure at $90 \% \mathrm{RH}$ is probably incomplete as the 001 reflection is positioned at $10.6 \pm 0.3 \AA$ after 4 hours of equilibration. It is worth mentioning that these changes are associated with intensity variations of the band located at $30^{\circ} 2 \theta \mathrm{CuK}_{\alpha}$ (Figure $5 \mathrm{~A}$ and $\mathrm{B}$ ). The intensity of this signal decreases with increasing temperature or decreasing relative humidity. 

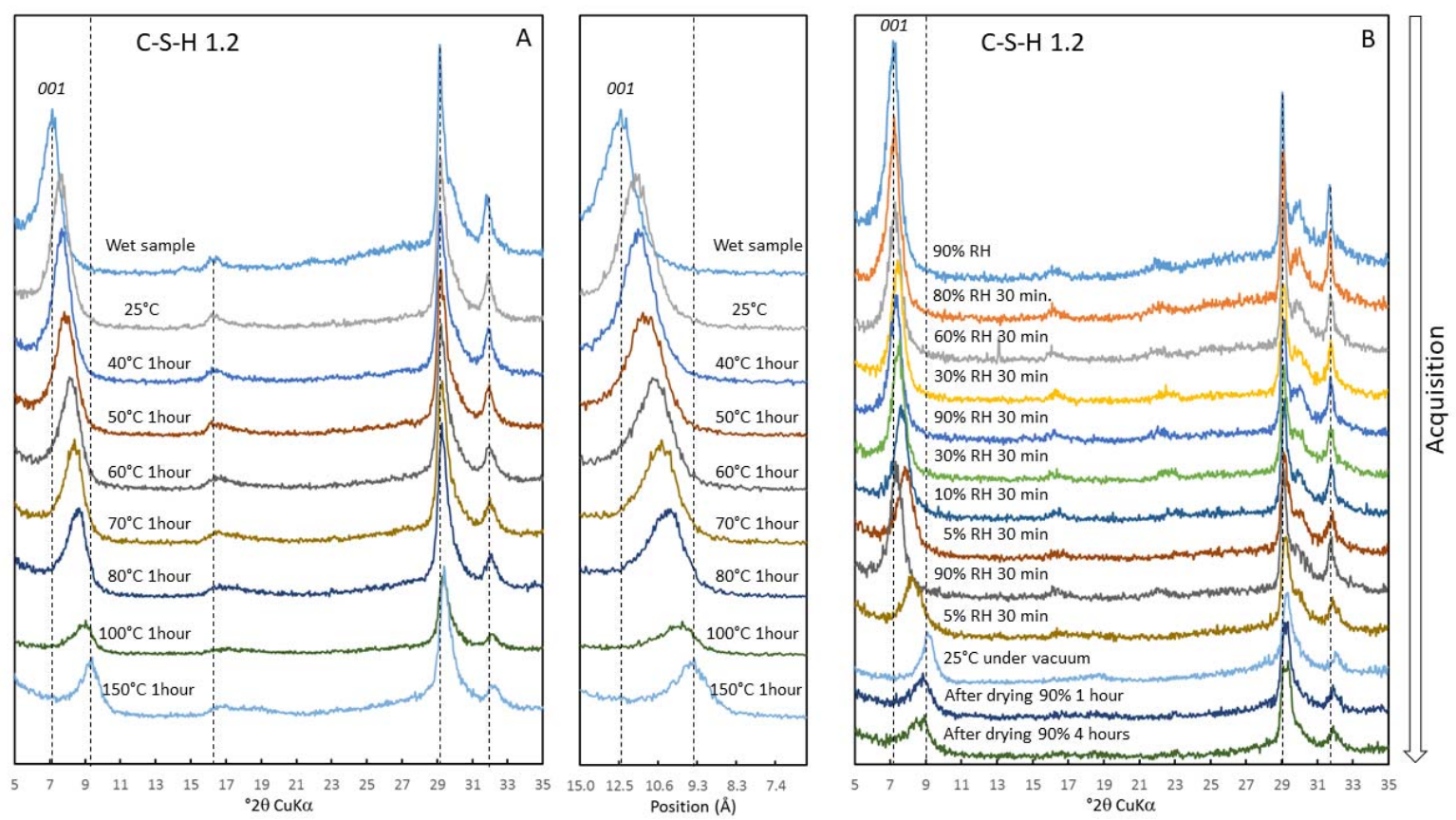

Figure 5 Experimental XRD patterns of $\mathrm{C}-\mathrm{S}-\mathrm{H} 1.2$ as a function of temperature $(A)$ and of relative humidity (B)

The behavior of C-S-H 1.6 (Figure 6) is very similar to that of C-S-H 1.2 with minor differences in the position of the 001 reflection.
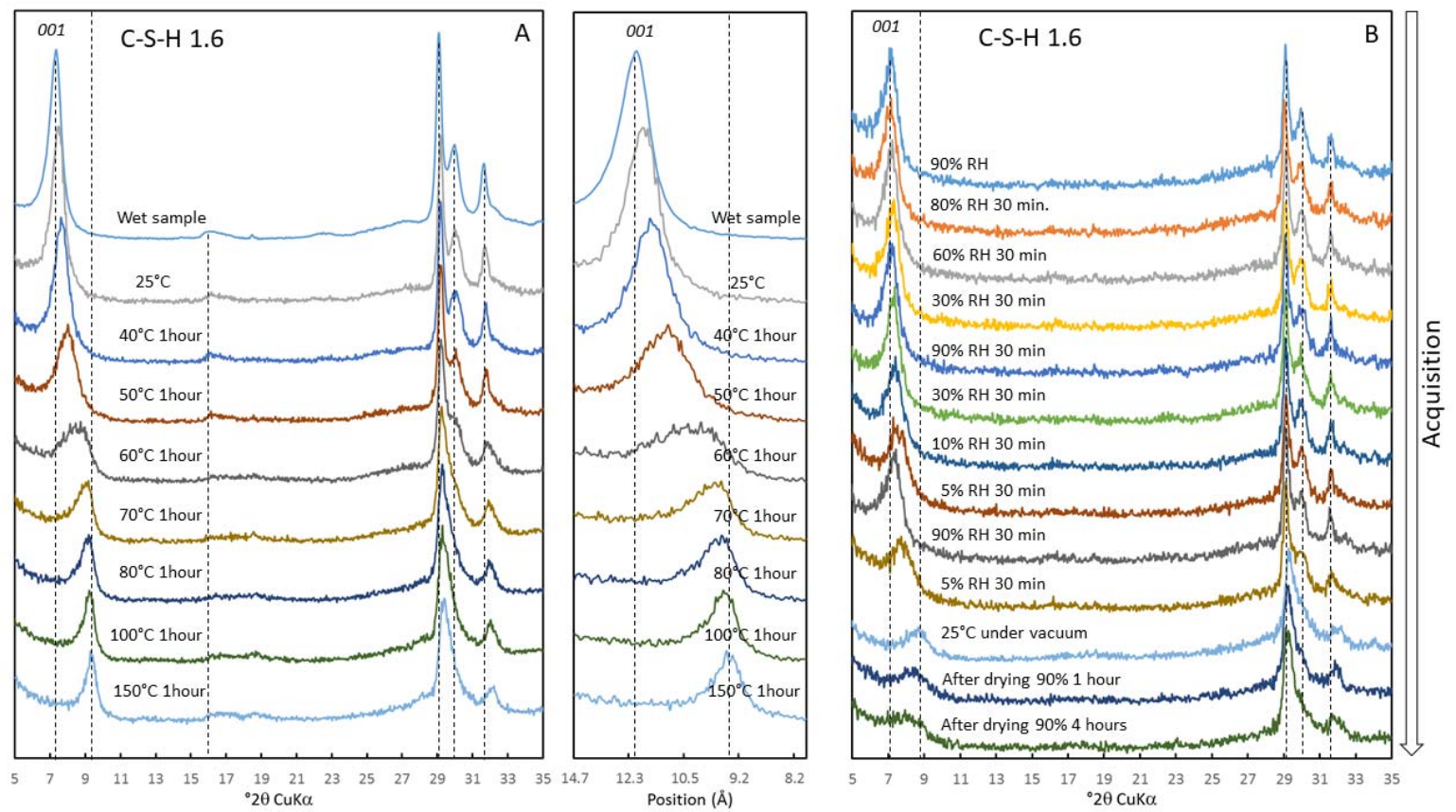

Figure 6 Experimental XRD patterns of $\mathrm{C}-\mathrm{S}-\mathrm{H} 1.6$ as a function of temperature $(A)$ and of relative humidity $(B)$

The changes in the position of the 001 reflection are generally used as a proxy for estimating the variation of the layer-to-layer distance. Still, in the case of nanocrystalline phases such as C-S-H, particular care must be taken. Indeed, in such structures, parameters such as the mean number of 
stacked layers or interstratification can induce significant shifts in the position of the $00 /$ reflections. To overcome this difficulty, it is much more relevant to determine the layer-to-layer distance from quantitative modeling of XRD patterns ${ }^{12,21}$, as performed for instance by Roosz, et al. ${ }^{17}$. XRD modeling of $00 /$ reflections has been extensively discussed for clay minerals ${ }^{37}$ and more recently for $\mathrm{C}-\mathrm{S}-\mathrm{H}^{21}$ and AFm phases ${ }^{43}$. Figure 7 displays the results from the modeling exercise undertaken in this study, while Table 3 lists the refined parameters.
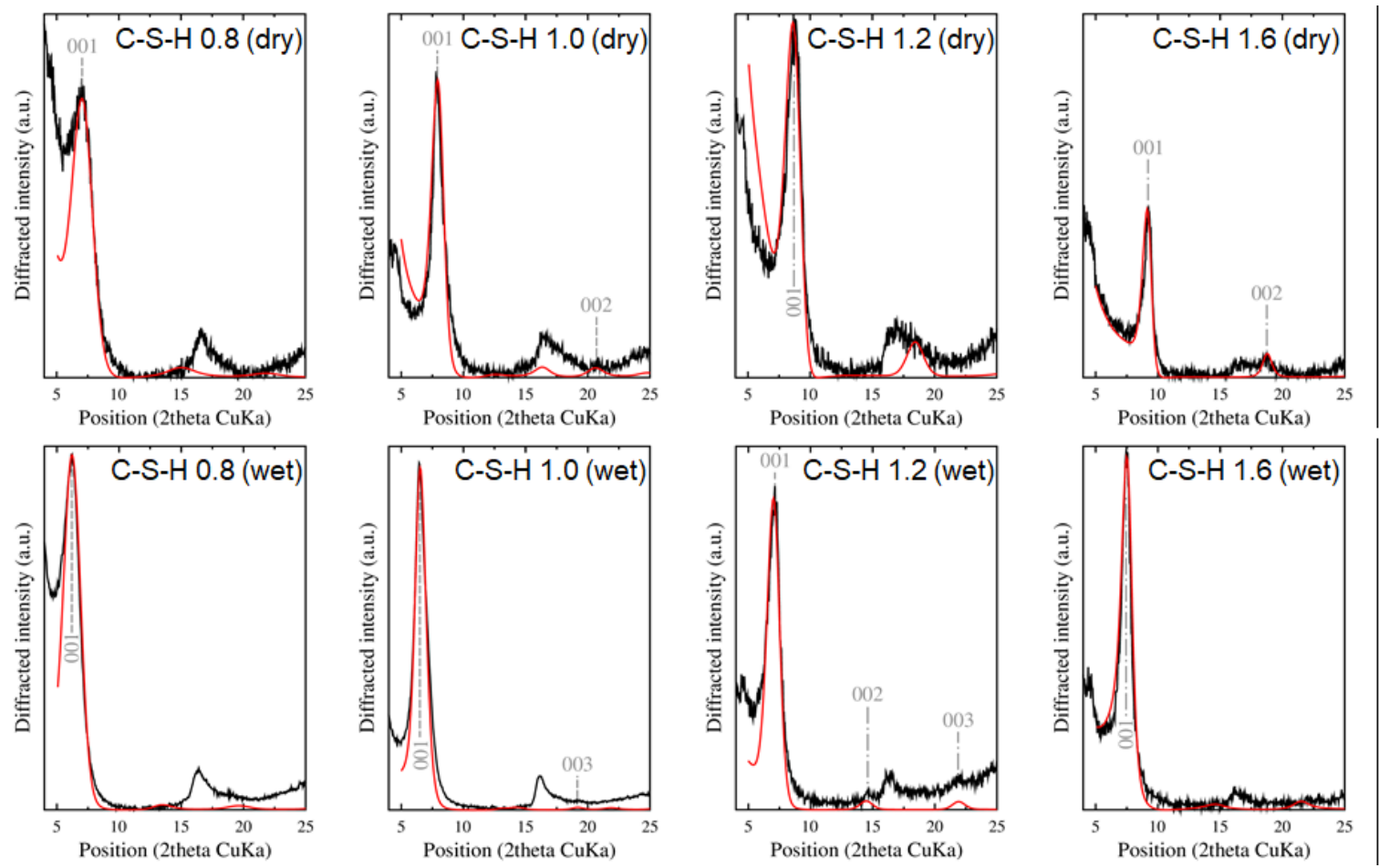

Figure 7 Experimental (black solid line) and calculated (red solid line) XRD patterns of, from left to right, C-S-H 0.8, 1.0, 1.2 and 1.6 under dried conditions (top) and fully hydrated state (bottom). All observable maxima are indexed (gray dashed line and associated text).

As in this procedure, only $00 /$ reflections are considered. The peaks corresponding to other reflections such as the asymmetric peaks located around $16^{\circ} 2 \theta$ (CuK $\alpha$ ) are not fitted. In comparison with clay minerals for which: (i) oriented preparations can be obtained using well-established protocols; (ii) various chemical exchange treatments can be performed to induce additional constraints on modeling, the case of $\mathrm{C}-\mathrm{S}-\mathrm{H}$ is trickier. Consequently, the fitting parameters obtained must be taken with some caution because no whole series of $00 /$ reflections could be systematically modeled. We note however that not only the 001 reflection was be observed for some samples (see indexed maxima in Figure 7) and, in this case, the data modeling reproduced both the position and the intensity of these additional reflections. Tendencies can be derived from this treatment. First of all, if one considers the dry samples, $\mathrm{C}-\mathrm{S}-\mathrm{H}$ with a $\mathrm{Ca} / \mathrm{Si}$ ratio $\geq 1.2$ can be modeled using a single component with a layer-to-layer distance of $9.6 \AA$. This is not the case for $\mathrm{Ca} / \mathrm{Si}$ ratios $\leq 1.0$. Indeed for these samples, one additional component at 11.3-12 $\AA$ had to be used to correctly reproduce the experimental patterns. This higher "complexity" of the samples with low $\mathrm{Ca} / \mathrm{Si}$ ratios is also apparent in the wet state. Indeed, fitting the experimental patterns of these samples systematically requires the presence of two components. In most cases, when two components are required in the fit, a Reichweite parameter equal to 0 (random interstratification) is the general rule. The only exception to this rule is provided by C-S-H 1.0, for which a Reichweite parameter equal to 1 (Table 3 ) indicates ordered interstratification, and the $\mathrm{P}_{\text {minor-minor }}$ of 
0.75 showed a strong tendency toward segregation. This could be considered as coherent with STEM images (Figure 2) if one assumed that this image is representative of an exceptional degree of segregation in this sample. For C-S-H 1.0, differences can be observed between the dry and wet state. Indeed, in the dry state, the stacking mode suggests partial ordering, whereas a tendency toward segregation is observed in the wet state. The evolution of coherent scattering domains (termed CSD, in Table 3) along a normal to the layer plane displays two main tendencies. (i) higher $\mathrm{Ca} / \mathrm{Si}$ ratios lead to higher CSDs (even if the sample at $\mathrm{Ca} / \mathrm{Si}=1$ does not follow this trend); (ii) CSDs in the wet state appear slightly higher than in the dry state. However, in every sample, the low mean number of layers stacked $(<7)$ means that the relationship between CSD and actual crystal size must be determined with extreme care and by bearing in mind that the two parameters are not directly linked.

Table 3 Parameters used for modeling the XRD patterns. (N/A. means not applicable)

\begin{tabular}{cccccccccc}
\hline & \multicolumn{2}{c}{ C-S-H 0.8 } & \multicolumn{2}{c}{ C-S-H 1 } & \multicolumn{2}{c}{ C-S-H 1.2} & \multicolumn{2}{c}{ C-S-H 1.6 } \\
& Dry & Wet & Dry & Wet & Dry & Wet & Dry & Wet \\
\hline \% 9.6 & 30 & 0 & 51 & 0 & 100 & 0 & 100 & 30 \\
$\%(11.3$ to $12 \AA)$ & 70 & 30 & 49 & 45 & 0 & 100 & 0 & 70 \\
$\% 13.9 \AA$ & 0 & 70 & 0 & 55 & 0 & 0 & 0 & 0 \\
Reichweite & 0 & 0 & 1 & 1 & N/A & N/A & N/A & 0 \\
PMinorMinor & 0.3 & 0.3 & 0.2 & 0.75 & N/A & N/A & N/A & 0.7 \\
CSD (mean number of layers & 2.5 & 3.25 & 5.5 & 6.5 & 4.5 & 4.5 & 7.5 & 8 \\
stacked parallel to each other) & & & & & & & & \\
\hline
\end{tabular}

Near-infrared diffuse reflectance under controlled water pressure. Figure 8 presents the near-infrared spectra of the three analyzed C-S-H samples under wet and dry conditions. Two main spectral regions corresponding to water features can be observed on the spectra. The first domain between 4500 and $5500 \mathrm{~cm}^{-1}$ corresponds mainly to the combination of water stretching $\left(\mathrm{V}_{\mathrm{OH}}\right)_{\mathrm{w}}$ and water bending mode $\left(\delta_{\mathrm{HOH}}\right)^{44}$. The second region, around $7000-7300 \mathrm{~cm}^{-1}$, corresponds to combinations and overtones of various $\left(\mathrm{V}_{\mathrm{OH}}\right)_{\mathrm{w}}$ as well as overtones of $\mathrm{v}_{\mathrm{OH}}$ of structural hydroxyl groups. Under vacuum, (Figure 8 , right), the signals with strong water contribution, i.e. around $5200 \mathrm{~cm}^{-1}$ and around $7000-7300 \mathrm{~cm}^{-1}$, exhibit a significant intensity decrease. Furthermore, under vacuum, a sharp band at $7320 \mathrm{~cm}^{-1}$ clearly appears for the three C-S-H samples. It corresponds to the overtone of the $\mathrm{Si}-\mathrm{OH}$ stretching of free $\mathrm{SiOH}$ groups on mineral surfaces ${ }^{45}$. The band at $4550 \mathrm{~cm}^{-1}$ is a combination of the $\mathrm{O}-\mathrm{H}$ stretching and bending mode of the SiOH species ${ }^{45}$. The main feature of the C-S-H spectra is the decreasing intensity of the $4550 \mathrm{~cm}^{-}$ ${ }^{1}$ band with increasing $\mathrm{Ca} / \mathrm{Si}$ ratio. 

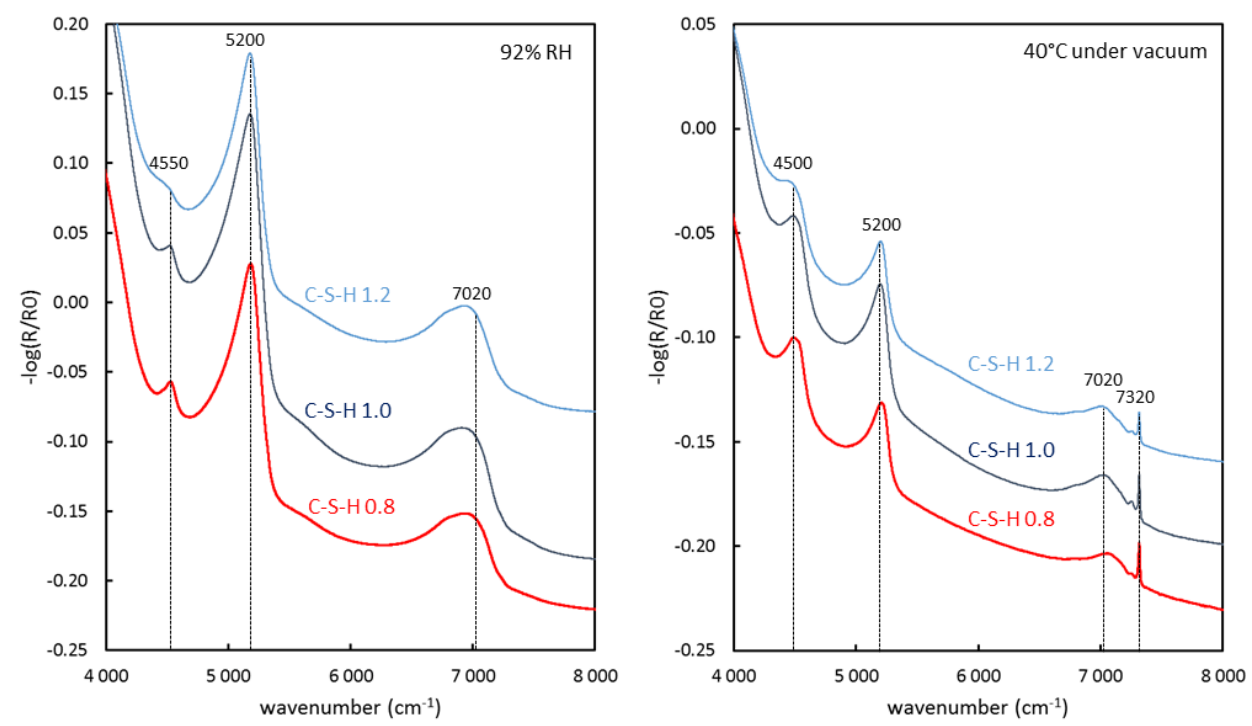

Figure 8 Near-IR diffuse reflectance spectra of C-S-H samples under wet and dry conditions

For each C-S-H sample, near-infrared diffuse reflectance spectra are acquired at different RHs, starting from a high RH down to $40{ }^{\circ} \mathrm{C}$ under vacuum before rehydrating the sample up to $86 \%$ RH. Figure 8 suggests that the $\mathrm{Ca} / \mathrm{Si}$ ratio does not have a strong influence on NIR signals. For that reason, in the following, the description of changes with $\mathrm{RH}$ will be limited on sample $\mathrm{C}-\mathrm{S}-\mathrm{H}$ 1.2. Figure 9 displays the near-infrared spectra obtained in desorption and adsorption for this sample. Zooms on the desorption in ranges between 4000 and $6000 \mathrm{~cm}^{-1}$ and between 6000 and $7500 \mathrm{~cm}^{-1}$ are also presented. In both regions, the signals display a smooth continuous decrease of intensity with decreasing RH down to 0 $\%$. Placing the sample under vacuum at $40{ }^{\circ} \mathrm{C}$ provokes a significant further decrease in intensity. As already mentioned, the NIR region can also be used to yield quantitative information. Indeed, after normalizing the spectra on the combination $v+\delta$ modes of structural hydroxyls groups, the integrated area of the signals between 4500 and $6000 \mathrm{~cm}^{-1}$ is proportional to the amount of adsorbed water ${ }^{34}$.
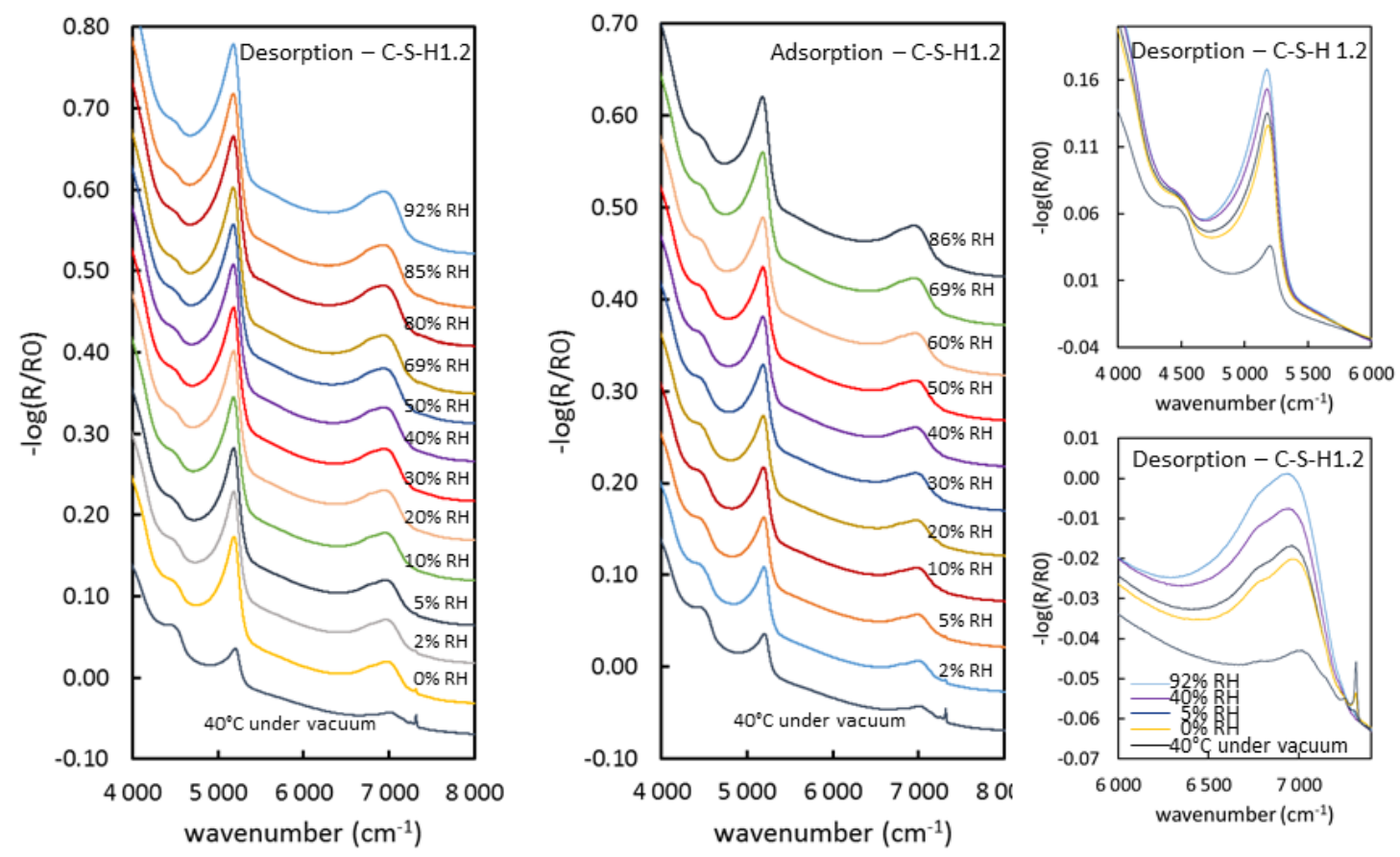
Figure 9 Near IR diffuse reflectance spectra of C-S-H 1.2 under different relative water pressures from 0.92 to dry condition (desorption) and from dry to 0.86 (adsorption). On the right, desorption near IR diffuse reflectance spectra of C-S-H 1.2 in the spectral ranges of combination bands $\left(4000-6000 \mathrm{~cm}^{-1}\right)$ and of the overtone bands $\left(6000-8000 \mathrm{~cm}^{-1}\right)$ of water and structural hydroxyls.

Figure 10 presents the evolution of the signals of the two main regions, corresponding to water, for a given relative humidity of $69 \% \mathrm{RH}$ during desorption and adsorption. The intensity of the signals obtained upon adsorption was always lower than desorption for a given relative humidity (Figure 10A and B). The water absorption bands are also slightly shifted between wet and dry conditions. Figure $10 \mathrm{C}$ displays the evolution of the integrated area as a function of relative water pressure normalized on the dried state. As displayed in Figure 9, the desorption isotherm is acquired first before drying the $\mathrm{C}-\mathrm{S}-\mathrm{H}$ samples at $40^{\circ} \mathrm{C}$ under vacuum and acquiring the adsorption branch. Desorption/adsorption isotherms are acquired for C-S-H 0.8, 1.0 and 1.2. The shape of the isotherms is similar for all the samples with desorption branches that are almost superimposed, residual water being detected even when a relative humidity of $0 \%$ is imposed on the atmosphere. Heating under vacuum is necessary to extract the corresponding water molecules. Indeed, even after conditioning of the sample at $40{ }^{\circ} \mathrm{C}$ under vacuum, signals corresponding to adsorbed water are still present (Figure $10 \mathrm{~A}$ and $\mathrm{B}$ ). The adsorption branches differ in the amount of adsorbed water, lower $\mathrm{Ca} / \mathrm{Si}$ ratios leading to higher adsorbed amounts.
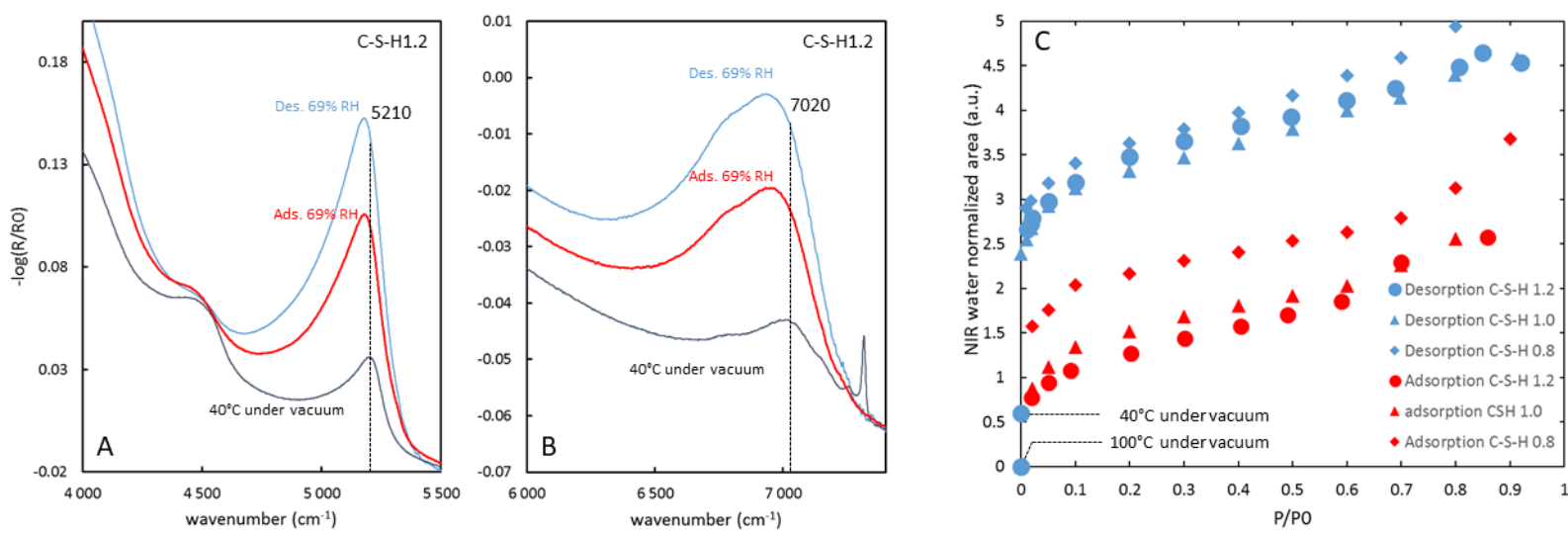

Figure 10 Near-IR diffuse reflectance spectra of C-S-H $1.2(A)$ in the range of combination bands of water, $(B)$ in the range of overtone bands of water and structural hydroxyls at a relative humidity of 69\%RH during desorption (Des.) and adsorption (Ads.). (C) Water desorption/adsorption isotherm obtained by the integration of the signals between 4750 and $5500 \mathrm{~cm}^{-1}$ for C-S-H $0.8,1.0$ and 1.2

Water vapor isotherm. The water vapor adsorption-desorption isotherm of C-S-H 1.2 is presented in Figure 11A, while Table 4 lists the surface areas obtained from the treatment of the isotherms of all the investigated samples. The specific surface area derived from the BET equation applied to the adsorption branch using a cross-sectional area of $14.8 \AA^{2}$ for the water molecule, ( $\mathrm{S}_{\mathrm{BET}}$ ), (Table 4) decreased with increasing $\mathrm{Ca} / \mathrm{Si}$ ratio from 430 (C-S-H 0.6) down to $180 \mathrm{~m}^{2} \mathrm{~g}^{-1}$ (C-S-H 1.6). The associated BET $C$ energetic constants (not shown) evolved from 110 to 45 indicating a strong affinity of water for the CSH surfaces, in agreement with values used for highly bound water ${ }^{19,}{ }^{46}$. The calculation of $t$ plots from standard isotherms is adapted from Roosz, et al. ${ }^{17}$. The total surface areas deduced from the $t$-plot method are close to the BET values and the application of this method yields no micropores. Using this method, it is possible to plot the amount of water adsorbed on external surfaces for $\mathrm{C}-\mathrm{S}-\mathrm{H}$ and compare it with the experimental data (Figure 11A). For relative pressures up 
to 0.7 , both curves are superimposed, which shows that only external surfaces are involved in water adsorption. For higher RH values, the experimental curve deviates upward compared to the $t$-plot thus revealing the existence of capillary condensation in mesopores. The desorption branch never coincides with adsorption as it remains higher and parallel to the adsorption branch over the whole $\mathrm{RH}$ range. Suchbehavior was observed for all C-S-H samples and has previously been described in the literature, where it was interpreted as corresponding to a partial reincorporation of interlayer water ${ }^{17}$. Surface areas can also be calculated based on the desorption branch. The obtained values evolve from 560 to $310 \mathrm{~m}^{2} \mathrm{~g}^{-1}$ from C-S-H 0.6 to 1.6 (Table 4). TGA data at $150{ }^{\circ} \mathrm{C}$ (normalized on a dried mass) of C-S-H samples equilibrated at $60 \% \mathrm{RH}$ upon desorption from fully hydrated samples are also plotted in Figure 11A. The latter is located above the desorption branch and is in agreement with TGA data obtained by Roosz, et al. ${ }^{17}$. This discrepancy is certainly related to the sample history as in this case, desorption was carried out after the sample pretreatment and the adsorption branch.

Figure $11 \mathrm{~B}$ presents the desorption/adsorption isotherm of C-S-H 1.2 obtained by near-infrared spectra. In this case, and in agreement with our previous statement, the desorption branch that is obtained without any pretreatment of the sample is higher than that derived from adsorption volumetry and concurs with TGA data. In contrast, the adsorption branch that is acquired after a similar pretreatment to that used in adsorption volumetry is superimposed. A marginal difference is observed at high RH that can be tentatively assigned to differences in powder packing in both experiments, which could slightly change the size distribution of mesopores.

Table 4 Surface areas from BET theory and the t-plot method of the analyzed C-S-H samples measured from water vapor isotherms

\begin{tabular}{cccccc}
\hline \multicolumn{5}{c}{ Water vapor adsorption volumetry } \\
\hline \multicolumn{5}{c}{ BET } & \multicolumn{2}{c}{$t$ plot } \\
samples & $\begin{array}{c}\text { Vm } \\
\left(\mathrm{cm}^{3} / \mathrm{g} \mathrm{STP}\right)\end{array}$ & $\begin{array}{c}\mathrm{S}_{\text {BET }} \\
\left(\mathrm{m}^{2} / \mathrm{g}\right)\end{array}$ & Total surface area $\left(\mathrm{m}^{2} / \mathrm{g}\right)$ \\
\hline Nominal & Ca/Si ratio & & Adsorption & Adsorption & Desorption \\
Ca/Si & & & $\sigma=14.8 \AA$ & $\sigma=14.8 \AA$ & $\sigma=14.8 \AA$ \\
\hline C-S-H 0.6 & 0.6 & 110 & 430 & 400 & 560 \\
C-S-H 0.8 & 0.8 & 90 & 373 & 350 & 500 \\
C-S-H 1.0 & 0.98 & 70 & 277 & 290 & 450 \\
C-S-H 1.2 & 1.16 & 53 & 215 & 201 & 360 \\
C-S-H 1.6 & 1.44 & 45 & 180 & 175 & 310 \\
\hline
\end{tabular}



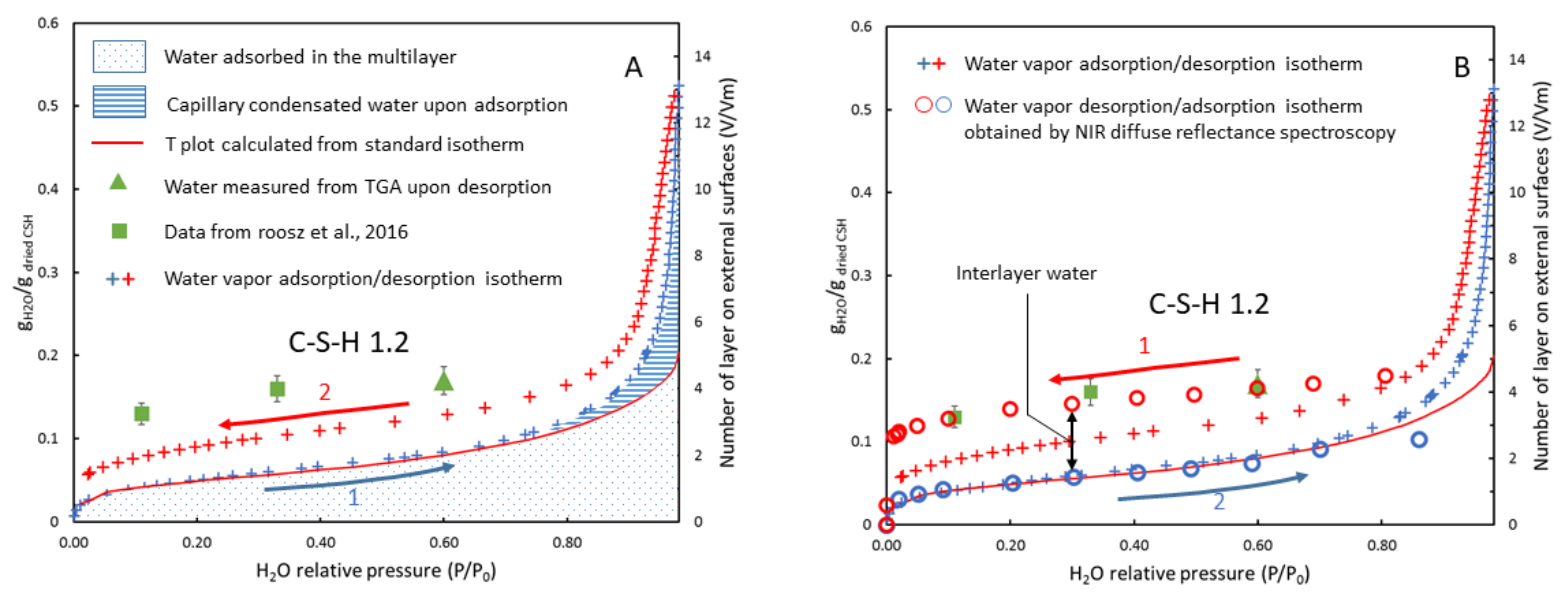

Figure 11 (A) Water vapor adsorption/desorption isotherm of C-S-H 1.2 and (B) water vapor desorption/adsorption isotherm obtained by near-infrared diffuse reflectance spectroscopy (open circles) added to the water vapor adsorption/desorption isotherm. Arrows indicate the pathway of acquisition

\section{Discussion}

In the present study, all the analyses were carried out with careful control of both humidity and drying. For samples such as $\mathrm{C}-\mathrm{S}-\mathrm{H}$, this is crucial, as conditioning (drying, preserved atmosphere) influences the C-S-H structure ${ }^{17,47-48}$. Sample conditioning clearly affects NMR spectra that are broader for dry samples (Figure 1) and the $d_{001}$ measured by XRD, as already shown by Richardson ${ }^{1}$. The spectral broadening is assigned to structural strains, such as shrinkage, that affect the density of the local order of Si atom-neighboring bonds ${ }^{11}$.

Structural evolution from low to high Ca/Si ratio.

At present, most studies describe $\mathrm{C}-\mathrm{S}-\mathrm{H}$ with a $\mathrm{Ca} / \mathrm{Si}$ ratio from 0.6 to 1.4 as structurally imperfect tobermorite ${ }^{8,12,49-50}$, with C-S-H stoichiometry being related to depolymerization of the Si chains and adsorption of $\mathrm{Ca}^{2+}$ ions at the surface of the layers ${ }^{40}$. Still, within this framework, the interlayer organization is not yet clearly determined.

For C-S-H with a $\mathrm{Ca}$ /Si ratio lower than 1 , NMR spectra obtained on wet samples display two distinctive narrow $Q_{2}$ and $Q_{2 b}$ contributions and the presence of $Q_{1}$ end-chains (Figure $1 A$ ). Such a sharp signal indicates that the Si chains are well ordered at short range over the "Dreierketten" structure chain repetition ${ }^{51}$. In parallel, in agreement with previous studies ${ }^{12-13,17}$, XRD patterns reveal low CSD with an average number of stacked layers ranging from 1 to 3 . This low stacking order can be linked to the local ordering of the silica chains and the evolution of hydroxyl surface density with decreasing $\mathrm{Ca} / \mathrm{Si}$ ratio, for which equilibrium $\mathrm{pH}$ ranges from 12.4 to 10.5 .

When the $\mathrm{Ca} / \mathrm{Si}$ ratio is equal to $1, \mathrm{NMR}$ spectra reveal a strong increase in the $\mathrm{Q}_{1}$ contribution (Figure $1 C$ ) associated with a decrease in the $Q_{2}$ and $Q_{2 b}$ peak intensity. This points toward a depolymerization of the Si chain with a mean chain length dropping from 18 to $6 \mathrm{Si}$ (Table 2) and a concomitant increase of end-chains, consistent with previous studies ${ }^{1,13}$. The broadening of the $Q_{1}$ and $Q_{2}$ NMR peaks (Figure $1 \mathrm{~A})$, indicates local structural disorder that could be linked with Si-O distance and angle distributions in the silicate units or differences in the number or species in the interlayer space as previously demonstrated by Pustovgar, et al. ${ }^{52}$. Along similar lines, Klur, et al. ${ }^{40}$ proved an increased inclusion of $\mathrm{Ca}$ in the interlayer bonded to $\mathrm{Q}_{1}$ or $\mathrm{Q}_{2}$, as a function of the $\mathrm{Ca} / \mathrm{Si}$ ration of $\mathrm{C}-\mathrm{S}-\mathrm{H}$. This phase transition 
occurring for $\mathrm{Ca} / \mathrm{Si}=1$ associated with an increase in the mean number of layers per crystallite and an interstratification of layers at 14 and $12 \AA$ in wet conditions (Table 3 and Figure 2).
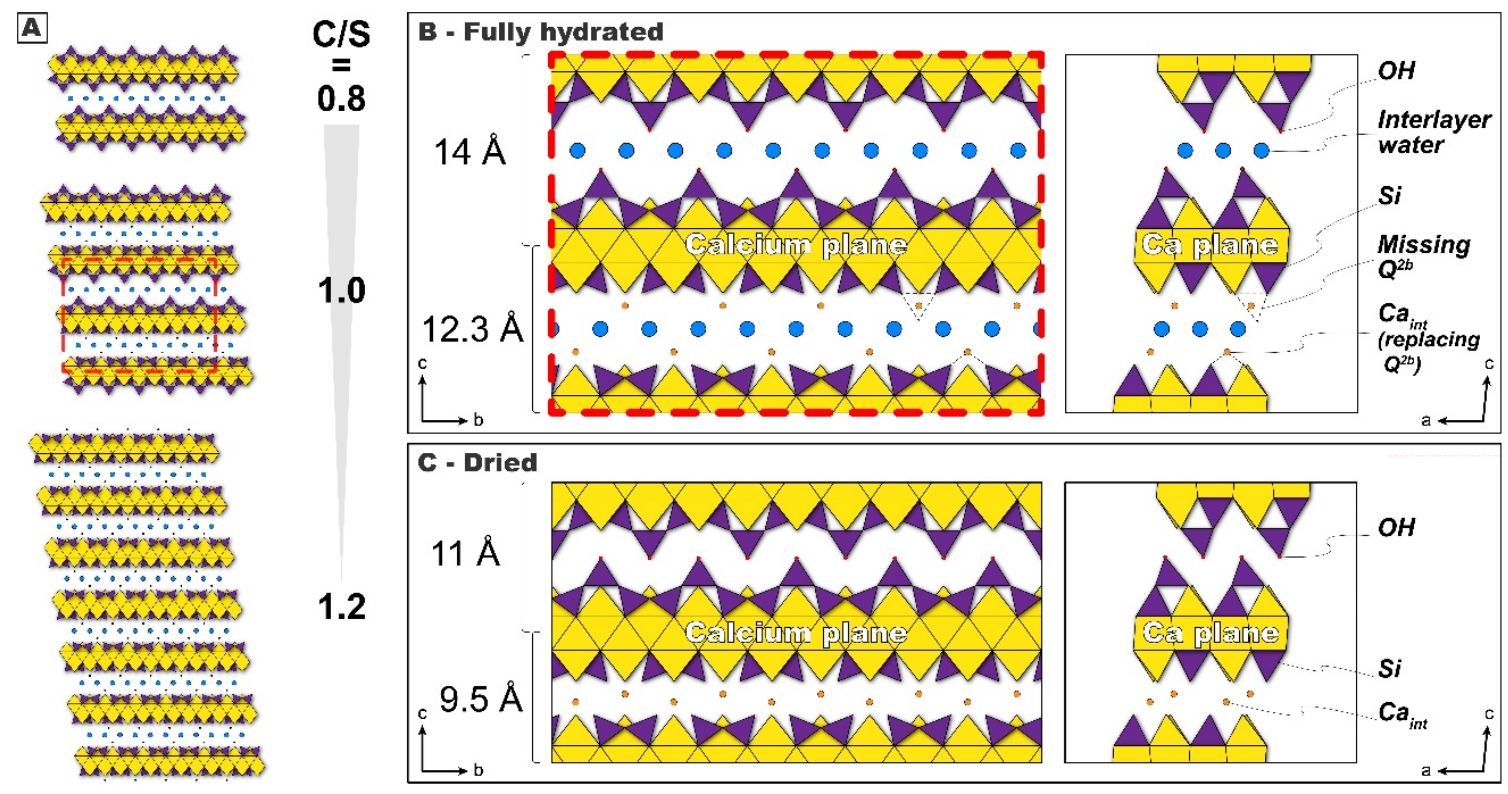

Figure 12 Sketch of C-S-H structure in wet and dry conditions. Figure A displays the stacking increase with increasing $\mathrm{Ca} / \mathrm{Si}$ ratio. Figures $\mathrm{B}$ and $\mathrm{C}$ propose a structure for the contribution of two distinct layer organizations of $\mathrm{C}-\mathrm{S}-\mathrm{H} 1.0$ in wet and dry conditions.

For $\mathrm{Ca} / \mathrm{Si}$ ratios between 1 and 1.6 , the $Q_{1}$ contribution increases linearly, while the $Q_{2}$ and $Q_{2 b}$ contributionssignificantly decrease. In particular for C-S-H 1.6, this latter contribution decreases down to $6 \%$ (Table 2), indicating that in this sample, almost all bridging tetrahedra are omitted. It must also be pointed out that for this $\mathrm{Ca} / \mathrm{Si}$ value, the mean chain length is as low as two, indicating a succession of dimers in the silicate chain with a proportion of vacant tetrahedral sites of $\approx 1 / 3$ (Table 2 ), consistent with previous studies ${ }^{1}$. As in the case of $\mathrm{C}-\mathrm{S}-\mathrm{H} 1.0$, the broadening of the NMR signals corresponding to $Q_{2}$ and $Q_{1}$ peaks indicates an increase in local disorder of the structure. In parallel, XRD patterns reveal an increase in the crystallite size, with a clear sharpening of the Bragg peak. The decrease of the full width at high maximum (FWHM) can be linked to an increase of the average number of layers per crystallite, a change in interstratification mode, and (or) an increase in the homogeneity of the layerto-layer distance (Table 3 and Figure 2). For the nominal C-S-H 1.6, the number of layers per crystallite is $\approx 8$ with a layer-to-layer distance of $\sim 12.2 \AA$.

The structural evolution of C-S-H with increasing $\mathrm{Ca} / \mathrm{Si}$ ratio is thus governed by two parameters that have inverse effects on structural conformations at short and medium range. For a $\mathrm{Ca} / \mathrm{Si}$ ratio lower than $1,{ }^{29} \mathrm{Si}$ NMR reveals an ordering of the silicate chains through the "dreierketten" structure and Xray diffraction patterns show a limited number of stacked layers (1 to 3 ) per crystallite. For a $\mathrm{Ca} / \mathrm{Si}$ ratio around 1 , a phase transition occurs in which the mean chain length decreases while Ca enters the interlayer space, as discussed in Cong and Kirkpatrick ${ }^{19}$, to compensate the negative charge resulting from the vacancy associated with the missing bridging tetrahedra. Such structural changes continues up to a nominal $\mathrm{Ca} / \mathrm{Si}$ ratio of 1.6, the value at which the proportion of the number of Si vacant sites in the Si chains reaches $1 / 3$ (dimer structure). In parallel, the Ca content in the interlayer space increases, and the number of layers stacked per crystallite increases (Figure 2). 
The above-described structural evolution of $\mathrm{C}-\mathrm{S}-\mathrm{H}$ is also reflected by the evolution of the stoichiometry of synthetic C-S-H with increasing $\mathrm{Ca} / \mathrm{Si}$ ratio. In the $11 \AA$ tobermorite structure ${ }^{28}$, with 7-fold coordinated $\mathrm{Ca}$ sheets sandwiched between silicate tetrahedral chains, and crystallites with small coherent scattering domains, the nominal calculated $\mathrm{Ca} / \mathrm{Si}$ ratio is $2 / 3$. Such a structure is coherent with what is observed for $\mathrm{C}-\mathrm{S}-\mathrm{H} 0.6$ and 0.8 . Considering the structural evolution evinced on NMR data, for C-S-H 1.0, 1.2 and 1.6, the $\mathrm{Ca} / \mathrm{Si}$ ratio should increase to $0.83,0.92$ and 0.96 , respectively, i.e. a value significantly lower than those measured experimentally (Table 1 ) as previously shown by Grangeon, et al. ${ }^{13}$ and Cong and Kirkpatrick ${ }^{19}$. Consequently, this means that for such high $\mathrm{Ca} / \mathrm{Si}$ ratios, additional calcium ions saturate the charge due to missing bridging tetrahedra. Such an interpretation is validated to a certain extent by the charge balance calculations ${ }^{19}$, and we propose that interlayer calcium ions are not in symmetric configuration, but mainly covalently bonded at the surface of the layer sharing oxygen on one side with silica tetrahedral and with water on the other side, as displayed schematically in Figure 12.

\section{Hydration properties and interlayer organization}

In order to probe the structural changes occurring along the water desorption/adsorption isotherm (Figure 11), we followed changes in the layer-to-layer distance $d_{001}$ with varying relative water pressure and temperature (Figure 3 to Figure 6).

The evolution of the layer-to-layer distance is a direct indicator of the swelling/shrinkage ability of layered compounds. In the case of $\mathrm{C}-\mathrm{S}-\mathrm{H}$, such a parameter depends on the $\mathrm{Ca} / \mathrm{Si}$ ratio and several authors analyzed long ago the relationship between the position of the 001 reflection and the $\mathrm{Ca} / \mathrm{Si}$ ratio of C-S-H phases ${ }^{27,48,53}$. Recent studies ${ }^{1,13}$ investigated this parameter in more detail revealing a shift of the 001 reflection toward low $d$-spacing values with an increase in the $\mathrm{Ca} / \mathrm{Si}$ ratio (Figure 13). Such a shift is assigned to an evolution of the relative abundances of $\sim 14, \sim 11.3$, and $\sim 9.6 \AA$ layer-tolayer distances as a function of the $\mathrm{Ca} / \mathrm{Si}$ ratio, with these layer-to-layer distances being possibly interstratified within a given crystallite ${ }^{21}$. Still, all the data appear rather scattered with significant changes for a given $\mathrm{Ca} / \mathrm{Si}$ ratio, which is probably due to changes in hydration conditions, or in drying procedures of the analyzed samples ${ }^{17}$.

The XRD patterns collected in the present study (Figure 3 Figure 5toFigure 6) clearly evidence that, whatever the $\mathrm{Ca} / \mathrm{Si}$ ratio, the layer-to-layer distance decreases with decreasing relative humidity, as already shown by Cong and Kirkpatrick ${ }^{54}$. Still, depending on the Ca/Si ratio, different tendencies can be deduced from the modeling of the XRD patterns. For a $\mathrm{Ca} / \mathrm{Si}$ ratio $>1$, in both wet and dry conditions, one single layer-to-layer distance is necessary to fit the patterns, from 12-12.2 $\AA$ in wet conditions and at $9.6 \AA \AA$ in dry conditions. At a Ca/Si ratio of 1, to reproduce XRD patterns, consideration must be given to the interstratification of layers with layer-to-layer distances of $11.3-12$ and $14 \AA$ and 9.6 and $11.3-12 \AA$ in wet and dry conditions, respectively. For $\mathrm{Ca} / \mathrm{Si}=0.8$, in wet conditions a homogeneous layer-to-layer distance of $14 \AA$ allows the patterns to be reproduced. In the dry state, an interstratification between 9.6 and 11.3-12 ̊ layer-to-layer distances leads to satisfactory fits. However, in view of the absence of the systematic presence of a series of $00 /$ reflections, these results must be taken with caution. In any case, for a low $\mathrm{Ca} / \mathrm{Si}$ ratio in wet conditions, the difference between wet and dry values for layer-to-layer distances corresponds to the size of one to two water molecules, whereas at a high $\mathrm{Ca} / \mathrm{Si}$ ratio, the distance corresponds to the size of one water molecule, i.e. $2.4-2.8$ A. 
Furthermore, it appears that whatever the $\mathrm{Ca} / \mathrm{Si}$ ratio, at least one plane of water molecule can be present in the structure depending on the hydration state of the material. This is reminiscent of what happens in tobermorite, which displays a transition from 14 to $11 \AA$ upon drying ${ }^{55}$. The scattering in the observed position of the 001 reflection for a given $\mathrm{Ca} / \mathrm{Si}$ ratio (Figure 13A), as compiled in recent articles $^{1,13}$ is thus likely indicative of various drying states of the studied samples that result in different interlayer water contents.

In order to further analyze this phenomenon, it is fruitful to plot the evolution of the position of the layer-to-layer distance along the water vapor adsorption-desorption isotherm taking into account various hydration/dehydration cycles (Figure 13B), and bearingin mind that this position may be approximately $1 \AA$ (or more) higher than the actual layer-to-layer distance (compare Figures 6 and 7 in Grangeon, et al. $\left.{ }^{56}\right)$. Focusing on the case of C-S-H 1.2, that exhibits rather coherent stacking along the c direction, upon dehydration from $90 \% \mathrm{RH}$ to $30 \% \mathrm{RH}$, the position of the 001 reflection shifts toward low $d$-spacing values, then back when the $\mathrm{RH}$ is increased back up to $90 \%$. Upon further dehydration, down to $5 \% \mathrm{RH}$, the position of the 001 reflection reaches $10.7 \AA$ (Figure 13B), which might indicate the presence of collapsed layers mixed with fully hydrated layers. Upon rehydration, the sample exhibits almost reversible behavior. Further dehydration using higher temperatures and/or vacuum leads to a lower position of the 001 reflection values close to $9.5 \AA$. Still, as shown by near IR spectroscopy, heating to $40{ }^{\circ} \mathrm{C}$ under vacuum is not enough to remove all adsorbed water in $\mathrm{C}-\mathrm{S}-\mathrm{H}$, demonstrating the very high affinity of water for these materials. When rehydrating the sample after this vacuum treatment, the position of the 001 reflection shifts toward high $d$-spacing values with increasing $\mathrm{RH}$, but even at $90 \% \mathrm{RH}$ the position of the 001 reflection $(10.8 \AA)$ is lower than that obtained in the fully hydrated state (12-12.5 $\AA$ ). By looking at Figure $13 \mathrm{~B}$, it appears that for a given sample, depending on hydration conditions and sample history, a wide range of apparent distances can be obtained, which further illustrates that the scattering in distances reported in the literature is certainly linked to differences in hydration conditions and sample preparation procedures. The hysteretic behavior observed after strong dehydration could be assigned to the presence of collapsed layers that are unable to rehydrate due to local thermodynamic effects with free energy barriers ${ }^{57}$. The occurrence of layers with various hydration states inside a sample is likely related to a heterogeneous charge distribution that also leads to a heterogeneous distribution of interlayer cations. Such a behavior is observed for swelling clay minerals ${ }^{58}$, but the situation for C-S-Hs is clearly more complex as in addition to heterogeneity, different species that are covalently bonded at the surface of the silicate chains coexist in the interlayer of $\mathrm{C}-\mathrm{S}-\mathrm{H}^{52}$. 

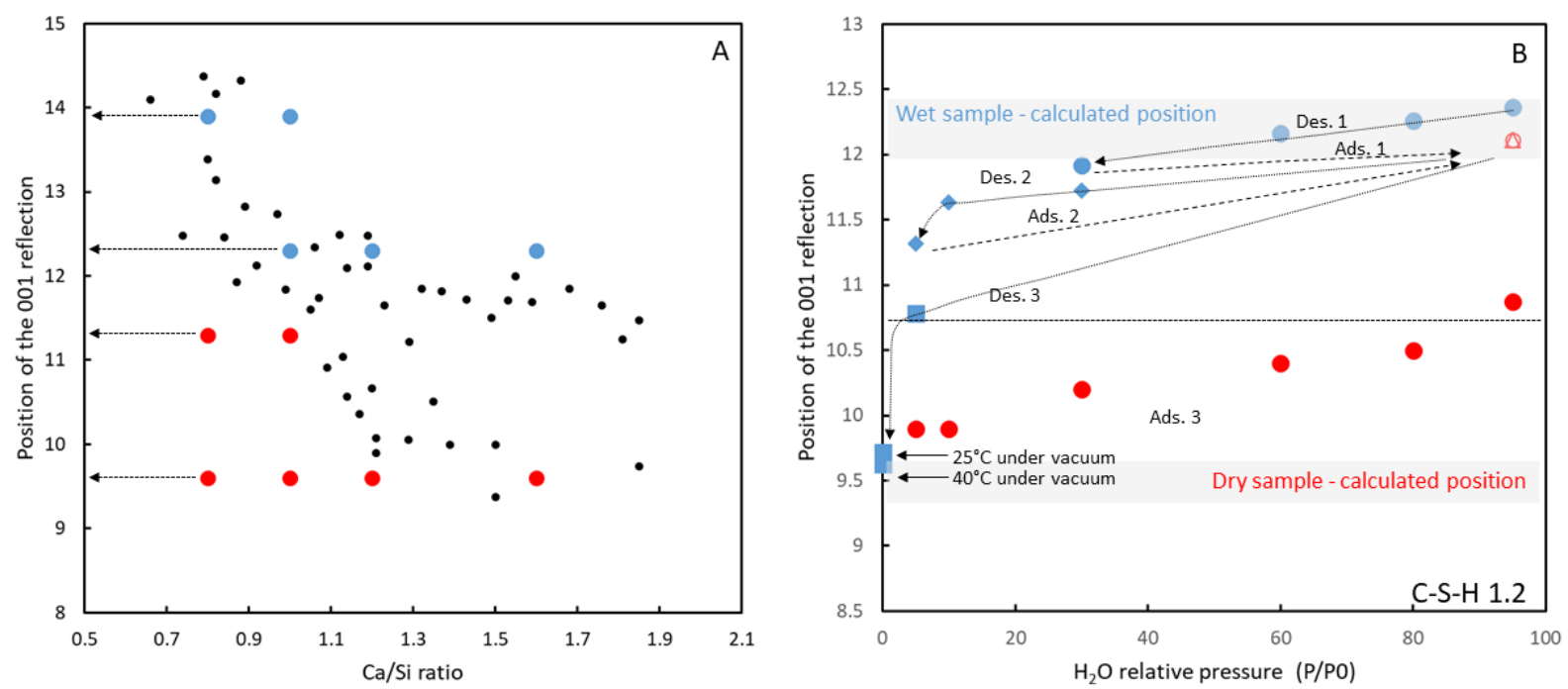

Figure 13 (A) Layer-to-layer distance of $\mathrm{C}-\mathrm{S}-\mathrm{H}$ as a function of $\mathrm{Ca}$ /Si ratio. Black points are experimental data taken from Figure 1 in Richardson ${ }^{1}$. The blue and red points are the positons calculated from the presented XRD patterns in wet and dry conditions (Table 3), respectively. (B) Evolution for C-S-H 1.2 of the apparent positions of the 001 reflection as a function of relative water pressure (Des. and Ads. are for desorption and adsorption). Doted and dashed arrows indicate the cycling pathway of drying and rewetting of the sample. The grey bands correspond to XRD calculated positions (Table 3).

The tendency described here in detail for C-S-H 1.2, i.e. complex hydration behavior and hysteresis in rehydration after pretreatment under vacuum, is also observed with the other samples both by XRD (Figure 4 and Figure 6) and by near IR diffuse reflectance spectroscopy (Figure 10C).

As discussed above, when the $\mathrm{pH}$ of the solution increases (Table 1, i.e. increase of the $\mathrm{Ca} / \mathrm{Si}$ ratio of $\mathrm{C}-\mathrm{S}-\mathrm{H})$, hydrogen atoms of the hydroxylated surface are removed and the resulting negative surface charges are compensated by $\mathrm{Ca}^{2+}$ or $\mathrm{CaOH}^{+}{ }^{52}$. This interlayer $\mathrm{Ca}^{2+}$ is strongly physisorbed to the surface ${ }^{1,20}$ which leads to a very strong bonding of water molecules. This is illustrated in the present study by the presence of residual water molecules after drying (Figure 10). As already mentioned, the $3 \AA$ decrease in the layer-to-layer distance between wet and dry conditions likely indicates the presence of one monolayer of water separating two adjacent silicate layers. Such a configuration is significantly different from that observed in $\mathrm{Ca}^{2+}$-exchanged swelling hydroxylated clay minerals, in which $\mathrm{Ca}^{2+}$ is located in the mid-plane and surrounded by water molecules but close to what could have been observed in Ca-exchange magadiite by Eypert-Blaison, et al. ${ }^{59}$ who observed a strong interaction between interlayer calcium ions and structural $\mathrm{SiO}^{-}$groups. In such a situation, it is likely that $\mathrm{C}-\mathrm{S}-\mathrm{H}$ water/cation interactions are not strong enough to displace $\mathrm{Ca}^{2+}$ from its initial position and interlayer water is stuck in the interlayer space exchanging strong interactions with both calcium ions and silicate layers.

To confirm such an interpretation, the evolution of the amount of interlayer water contribution as a function of RH was calculated. Such a treatment can be carried out by considering the evolution of the layer-to-layer distance along the water vapor desorption isotherm and by combining near-IR and volumetric water vapor isotherms (Figure 11B). The amount of interlayer water was then calculated by subtracting the desorption branch obtained by near-IR isotherm and the adsorption branch over a partial pressure of 0.1 to 0.5 . Figure $14 \mathrm{~A}$ displays the result of such a treatment. For a given $\mathrm{C}-\mathrm{S}-\mathrm{H}$ in a $\mathrm{RH}$ range from 0 to 0.5 , the amount of interlayer water is rather constant. Still, it increases with 
increasing $\mathrm{Ca} / \mathrm{Si}$ and as shown in Figure 14B, such an increase is linearly correlated to the amount of interlayer $\mathrm{Ca}$ ions. Such a result reinforces the vision of interlayer water being strongly linked to both $\mathrm{Ca}^{2+}$ ions and Si surfaces.
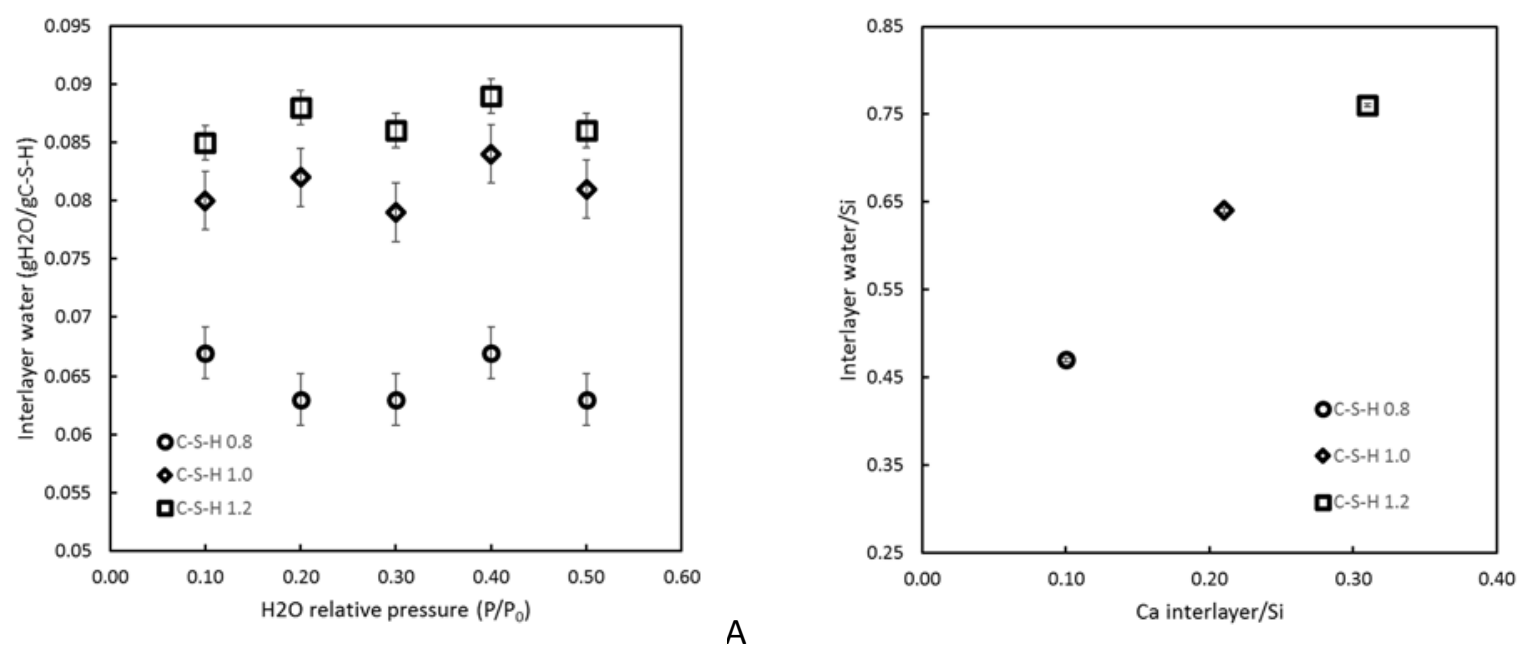

A

Figure 14 (A) Quantity of interlayer water as a function of relative humidity. (B) evolution of the interlayer water plotted as a function of the amount of interlayer calcium.

\section{Water content and porosity contribution of $C$-S-H interlayer water}

As shown for swelling clay minerals, when montmorillonite expands in water, the interlayer thickness increases, which is variable and depends on numerous parameter ${ }^{60}$, such as, among others, montmorillonite type, water activity, nature of exchangeable cations or dry density. In this case, various interlayer thicknesses can be observed depending on $\mathrm{RH}$, corresponding to different numbers of water layers $(1,2 \text { or } 3 \text { layers })^{61}$.

In the case of $\mathrm{C}-\mathrm{S}-\mathrm{H} \geq 1.2$, as shown above, in water saturated conditions ( $90 \% \mathrm{RH})$, the layer-to-layer distance, remains constant with only a water monolayer, while in the case of Ca-swelling hydroxylated clay minerals, two layers of water are quantified. This limited swelling behavior is linked to the disposition of $\mathrm{Ca}$ ions at the surface of the C-S-H layer. The layer of physisorbed Ca prevents the formation of a diffuse laye ${ }^{26}$ and calcium ions are probably not exchangeable. Due to this structure, the swelling of C-S-H appears not to be totally reversible, in the conditions of our experiments, and after strong drying less water is accommodated in the interlayer. The role of potential layer modifications induced by the drying procedure above $60^{\circ} \mathrm{C}$, suggested by changes in the in-plane lattice parameters, remains to be explored. Such modifications are however not an issue for the present study, which aimed at determining the structure of C-S-H interlayer space. Considering that in wet conditions the interlayer thickness is constant, with a monolayer of water with an extension perpendicular to the layer plane of about $3 \AA^{32}$, it is possible to estimate the porosity contribution of the interlayer water. Assuming a flat layered structure with dimers along the $\mathrm{Si}$ sheet $(\mathrm{Ca} / \mathrm{Si} \geq 1.2)$ and considering the structural parameters given in Table 5 , the volume of interlayer porosity in wet conditions accounts for $30 \pm 5 \%$ of the C-S-H particle. Thus, it must certainly be considered when assessing the porosity of cement materials but it must be pointed out that due to the cation and cation/water organization, the interlayer space is very unlikely to participate in cation transfers in cement.

Table 5 Structural parameters of C-S-H 


\begin{tabular}{|c|c|c|}
\hline Parameters & Hydrated & dried \\
\hline a $(\AA ̊ \cap) *$ & 6.71 & \\
\hline$b(\AA ̊) *$ & 7.31 & \\
\hline$d(00 I)(\AA ̊)$ & 12.3 & - \\
\hline$d(00 l)(\AA ̊)$ & - & 9.6 \\
\hline Unit cell volume $\left(\mathrm{cm}^{3}\right)$ & $6.0410^{-22}$ & $4.7910^{-22}$ \\
\hline Molecular weight $(\mathrm{g} / \mathrm{mol})$ & 675.9 & 595.2 \\
\hline Unit cell mass (g) & $1.1210^{-21}$ & $9.8810^{-22}$ \\
\hline
\end{tabular}

\section{Conclusion}

In a previous study ${ }^{17}$, we were able evidence the presence of different types of water in synthetic C-S$\mathrm{H}$ and emphasized the importance of maintaining water saturated conditions when studying C-S-H materials. Withcareful control of hydration and pretreatment conditions, the present paper analyzed in detail the structural evolution of $\mathrm{C}-\mathrm{S}-\mathrm{H}$ with various $\mathrm{Ca} / \mathrm{Si}$ ratios for various $\mathrm{RHs}$ by combining ${ }^{29} \mathrm{Si}$ MAS-NMR, water vapor adsorption volumetry, NIR-DR spectroscopy and XRD. We observed, as in previous studies, that with increasing $\mathrm{Ca} / \mathrm{Si}$ ratio, the crystal chemistry of $\mathrm{C}-\mathrm{S}-\mathrm{H}$ is controlled by the omission of bridging Si tetrahedral, accompanied by the inclusion of calcium ions in the interlayer to compensate the resulting charge deficit. In wet conditions, samples with low $\mathrm{Ca} / \mathrm{Si}$ ratios display an apparent layer-to-layer distance of around $14 \AA$ that falls to $\sim 12.2 \AA$ for $\mathrm{Ca} / \mathrm{Si}>1$, respectively. In this latter case, the difference in distance between the dry and wet state is around $3 \AA$, with slightly higher differences being observed in the former case. In all cases the distance between two adjacent layers in wet samples corresponds to the thickness of around one monolayer of water molecules. The amount of water is directly correlated to the amount of calcium ions present in the interlayer compensating the missing Si bridging tetrahedra. Clearly, for $\mathrm{C}-\mathrm{S}-\mathrm{H}$, cation hydration alone does not explain water adsorption features, and the interplay between water, cations and surface interactions controls the structuration of interlayer water molecules. The exact structure and location of water molecules remain ill-defined as some of the molecules could be engaged in the creation of silanol groups.

Finally, as already demonstrated for some $\mathrm{Ca}^{2+}$ silicates $^{49}$, because vibrational spectroscopies probe only very short times, the image of interlayer water derived from such techniques does not provide any dynamical information in the nanosecond to millisecond range. However, the structural complexity evidenced using vibrational techniques suggests potentially complex dynamics for water and ions in such a confined space, which could be approached using quasi-elastic and inelastic neutron scattering.

In terms of porosity, the hydrated interlayer space appears to account for $\approx 30 \%$ of the volume of wet $\mathrm{C}-\mathrm{S}-\mathrm{H}$. Such a contribution is far from negligible when assessing the porosity of cement materials. Still, in view of water/cation/surface interactions in the interlayer, this region is very unlikely to participate in the diffusion pathway of ions in these materials.

\section{Acknowledgements}

The work was conducted within the framework of an InterCarnot project CHYCANE. We are deeply grateful for the support of the MICA and BRGM Carnot institutes. ANDRA is also acknowledged for its financial support. Laurent Michot is greatly thanked for the fruitful discussion, corrections and comments. 


\section{References}

1. Richardson, I. G., Model structures for C-(A)-S-H(I). Acta Crystallographica Section BStructural Science Crystal Engineering and Materials 2014, 70, 903-923.

2. Taylor, H. F. W., Proposed sructure for calcium silicate hydrate gel. Journal of the American Ceramic Society 1986, 69 (6), 464-467.

3. Nicoleau, L., New Calcium Silicate Hydrate Network. Transportation Research Record 2010, (2142), 42-51.

4. Marty, N. C. M.; Grangeon, S.; Warmont, F.; Lerouge, C., Alteration of nanocrystalline calcium silicate hydrate (C-S-H) at pH 9.2 and room temperature: a combined mineralogical and chemical study. Mineralogical Magazine 2018, 79 (2), 437-458.

5. Pellenq, R. J. M.; Van Damme, H., Why does concrete set?: The nature of cohesion forces in hardened cement-based materials. Mrs Bulletin 2004, 29 (5), 319-323.

6. Delville, A., Electrostatic interparticle forces from swelling to setting. In Second Rilem workshop on hydration and setting: "Why does cement set?", Rilem editions ed.; Nonat, A., Ed. Rilem Editions: 1997; pp 37-62.

7. Picker, A.; Nicoleau, L.; Burghard, Z.; Bill, J.; Zlotnikov, I.; Labbez, C.; Nonat, A.; Cölfen, H., Mesocrystalline calcium silicate hydrate: $\mathrm{A}$ bioinspired route toward elastic concrete materials. Science Advances 2017, 3 (11), e1701216.

8. Nonat, A., The structure and stoichiometry of C-S-H. Cement and Concrete Research 2004, 34 (9), 1521-1528.

9. Roosz, C.; Vieillard, P.; Blanc, P.; Gaboreau, S.; Gailhanou, H.; Braithwaite, D.; Montouillout, V.; Denoyel, R.; Henocq, P.; Madé, B., Thermodynamic properties of C-S-H, C-A-S-H and M-S-H phases: Results from direct measurements and predictive modelling. Applied Geochemistry 2018, 92, 140-156.

10. Labbez, C.; Jonsson, B.; Pochard, I.; Nonat, A.; Cabane, B., Surface charge density and electrokinetic potential of highly charged minerals: Experiments and Monte Carlo simulations on calcium silicate hydrate. Journal of Physical Chemistry B 2006, 110 (18), 9219-9230.

11. Pellenq, R. J. M.; Lequeux, N.; Van Damme, H., Engineering the bonding scheme in C-S-H : the iono-covalent framework Cement and Concrete Research 2008, 38, 159-174.

12. Grangeon, S.; Claret, F.; Lerouge, C.; Warmont, F.; Sato, T.; Anraku, S.; Numako, C.; Linard, Y.; Lanson, B., On the nature of structural disorder in calcium silicate hydrates with a calcium/silicon ratio similar to tobermorite. Cement and Concrete Research 2013, 52, 31-37.

13. Grangeon, S.; Claret, F.; Roosz, C.; Sato, T.; Gaboreau, S.; Linard, Y., Structure of nanocrystalline calcium silicate hydrates: insights from $X$-ray diffraction, synchrotron $X$-ray absorption and nuclear magnetic resonance. J. Appl. Crystallogr. 2016, 49 (3).

14. Brunet, F.; Bertani, P.; Charpentier, T.; Nonat, A.; Virlet, J., Application of Si-29 homonuclear and $\mathrm{H}-1-\mathrm{Si}-29$ heteronuclear NMR correlation to structural studies of calcium silicate hydrates. Journal of Physical Chemistry B 2004, 108 (40), 15494-15502.

15. Powers, T. C.; Brownyard, T. L., Studies of the physical properties of hardened portland cement paste. Journal of American concrete institute 1948, Proceeding, 43.

16. Feldman, R. F.; Sereda, P. J., A new model for hydrated portland cement and its practical implications. Engineering Journal 1970, 53, 53-59.

17. Roosz, C.; Gaboreau, S.; Grangeon, S.; Prêt, D.; Montouillout, V.; Maubec, N.; Ory, S.; Blanc, P.; Vieillard, P.; Henocq, P., Distribution of water in synthetic calcium silicate hydrates. Langmuir 2016, 32, 6794-6805.

18. Brunauer, S., Further discussion of the helium flow results of R. F. Feldman. Cement and Concrete Research 1972, 2 (6), 749-753.

19. Cong, X.; Kirkpatrick, R. J., 29Si MAS NMR study of the structure of calcium silicate hydrate. Advanced Cement Based Materials 1996, 3 (3-4), 144-156. 
20. Jamil, T.; Javadi, A.; Heinz, H., Mechanism of molecular interaction of acrylate-polyethylene glycol acrylate copolymers with calcium silicate hydrate surfaces. Green Chemistry 2020, Medium: X; Size: p. 1577-1593.

21. Grangeon, S.; Claret, F.; Linard, Y.; Chiaberge, C., X-ray diffraction: a powerful tool to probe and understand the structure of nanocrystalline calcium silicate hydrates. Acta Crystallographica Section B-Structural Science 2013, 69, 465-473.

22. Manzano, H.; Moeini, S.; Marinelli, F.; van Duin, A. C. T.; Ulm, F. J.; Pellenq, R. J. M., Confined Water Dissociation in Microporous Defective Silicates: Mechanism, Dipole Distribution, and Impact on Substrate Properties. Journal of the American Chemical Society 2012, 134 (4), 2208-2215.

23. Pellenq, R. J. M.; Van Damme, H., Why Does Concrete Set?: The Nature of Cohesion Forces in Hardened Cement-Based Materials. MRS Bulletin 2011, 29 (5), 319-323.

24. Bonnaud, P. A.; Ji, Q.; Coasne, B.; Pellenq, R. J. M.; Van Vliet, K. J., Thermodynamics of Water Confined in Porous Calcium-Silicate-Hydrates. Langmuir 2012, 28 (31), 11422-11432.

25. Bonnaud, P. A.; Ji, Q.; Van Vliet, K. J., Effects of elevated temperature on the structure and properties of calcium-silicate-hydrate gels: the role of confined water. Soft Matter 2013, 9 (28), 64186429.

26. Bonnaud, P.; Coasne, B.; Pellenq, R., Solvated calcium ions in charged silica nanopores. Journal of Chemical Physics 2012, 137 (6), 064706.

27. Bayliss, P., Interlayer absorption in CSH(I). Cement and Concrete Research 1975, 5 (3), 221-

223.

28. Merlino, S.; Bonaccorsi, E.; Armbruster, T., The real structure of tobermorite $11 \AA \AA$ : normal and anomalous forms, OD character and polytypic modifications. European Journal of Mineralogy 2001, $13(3), 577-590$.

29. Gmira, A.; Pellenq, R. J. M.; Rannou, I.; Duclaux, L.; Clinard, C.; Cacciaguerra, T.; Lequeux, N.; Van Damme, H., A Structural Study of Dehydration/Rehydration of Tobermorite, a Model Cement Compound. In Studies in Surface Science and Catalysis, F. Rodriguez-Reinoso, B. M. J. R.; Unger, K., Eds. Elsevier: 2002; Vol. Volume 144, pp 601-608.

30. Lothenbach, B.; Nonat, A., Calcium silicate hydrates: Solid and liquid phase composition. Cement and Concrete Research 2015, 78, Part A, 57-70.

31. Massiot, D.; Fayon, F.; Capron, M.; King, I.; Le Calve, S.; Alonso, B.; Durand, J. O.; Bujoli, B.; Gan, Z. H.; Hoatson, G., Modelling one- and two-dimensional solid-state NMR spectra. Magnetic Resonance in Chemistry 2002, 40 (1), 70-76.

32. Hagymassy, J.; Brunauer, S.; Mikhail, R., Pore structure analysis by water vapor adsorption I. t-curve for water vapor. Journal of Colloid and Interface Science 1969, 29 (3).

33. Lippens, B. C.; de Boer, J. H., Studies on pore systems in catalysts: V. The t method. Journal of Catalysis 1965, 4 (3), 319-323.

34. Rinnert, E.; Carteret, C.; Humbert, B.; Fragneto-Cusani, G.; Ramsay, J. D. F.; Delville, A.; Robert, J.-L.; Bihannic, I.; Pelletier, M.; Michot, L. J., Hydration of a Synthetic Clay with Tetrahedral Charges: A Multidisciplinary Experimental and Numerical Study. The Journal of Physical Chemistry B 2005, 109 (49), 23745-23759.

35. Plançon, A., Diffraction by layer structures containing different kinds of layers and stacking faults. J. Appl. Crystallogr. 1981, 14, 300-304.

36. Plançon, A., New modeling of X-ray diffraction by disordered lamellar structures, such as phyllosilicates. American Mineralogist 2002, 87 (11-12), 1672-1677.

37. Drits, V. A.; Tchoubar, C., X-ray diffraction by disordered lamellar structures: Theory and applications to microdivided silicates and carbons. Springer-Verlag: Berlin, 1990; $\mathrm{p} 371$.

38. Claret, F.; Sakharov, B. A.; Drits, V. A.; Velde, B.; Meunier, A.; Griffault, L.; Lanson, B., Clay minerals in the Meuse-Haute marne underground laboratory (France): Possible influence of organic matter on clay mineral evolution. Clays and Clay Minerals 2004, 52 (5), 515-532.

39. Colombet, P.; Grimmer, A.-R.; Zanni, H.; Sozzani, P., Nuclear Magnetic Resonance Spectroscopy of Cement Based Materials. Springer-Verlag Berlin Heidelberg: 1998; p 430. 
40. Klur, I.; Pollet, B.; Virlet, J.; Nonat, A., C-S-H structure evolution with calcium content by multi nuclear NMR. Springer: Berlin, 1998.

41. Beaudoin, J. J.; Gu, P.; Myers, R. E., The fracture of C-S-H and C-S-H/CH mixtures. Cement and Concrete Research 1998, 28 (3), 341-347.

42. Grangeon, S.; Fernandez-Martinez, A.; Baronnet, A.; Marty, N.; Poulain, A.; Elkaïm, E.; Roosz, C.; Gaboreau, S.; Henocq, P.; Claret, F., Quantitative X-ray pair distribution function analysis of nanocrystalline calcium silicate hydrates: a contribution to the understanding of cement chemistry. J. Appl. Crystallogr. 2017, 50 (1), 14-21.

43. Marty, N. C. M.; Grangeon, S.; Elkaïm, E.; Tournassat, C.; Fauchet, C.; Claret, F., Thermodynamic and crystallographic model for anion uptake by hydrated calcium aluminate (AFm): an example of molybdenum. Scientific Reports 2018, 8 (1), 7943.

44. Yu, P.; Kirkpatrick, R. J.; Poe, B.; McMillan, P. F.; Cong, X., Structure of Calcium Silicate Hydrate (C-S-H): Near-, Mid-, and Far-Infrared Spectroscopy. Journal of the American Ceramic Society 1999, 82 (3), 742-748.

45. Carteret, C., Mid- and Near-Infrared Study of Hydroxyl Groups at a Silica Surface: H-Bond Effect. The Journal of Physical Chemistry C 2009, 113 (30), 13300-13308.

46. Sierra, R. Contribution à l'étude de I'hydratation des silicates cacliques hydrauliques; Laboratoires des ponts et chaussées: 1974.

47. Korpa, A.; Trettin, R., The influence of different drying methods on cement paste microstructures as reflected by gas adsorption: Comparison between freeze-drying (F-drying), Ddrying, P-drying and oven-drying methods. Cement and Concrete Research 2006, 36 (4), 634-649.

48. Matsuyama, H.; Young, J. F., Effects of $\mathrm{pH}$ on precipitation of quasi-crystalline calcium silicate hydrate in aqueous solution. Advances in Cement Research 2000, 12 (1), 29-33.

49. Taylor, H. F. W., Cement Chemistry (2nd Edition). London, 1992.

50. Garbev, K.; Beuchle, G.; Bornefeld, M.; Black, L.; Stemmermann, P., Cell dimensions and composition of nanocrystalline calcium silicate hydrate solid solutions. Part 1: Synchrotron-based $\mathrm{x}-$ ray diffraction. Journal of the American Ceramic Society 2008, 91 (9), 3005-3014.

51. Liebau, F., Structural chemistry of silicates: structure, bonding, and classification. Springer Science \& Business Media: 2012.

52. Pustovgar, E.; Sangodkar, R. P.; Andreev, A. S.; Palacios, M.; Chmelka, B. F.; Flatt, R. J.; d'Espinose de Lacaillerie, J.-B., Understanding silicate hydration from quantitative analyses of hydrating tricalcium silicates. Nature Communications 2016, 7, 10952.

53. Gutteridge, W. A.; Parrott, L. J., A study of the changes in weight, length and interplanar spacing induced by drying and rewetting synthetic CSH (I). Cement and Concrete Research 1976, 6 (3), 357-366.

54. Cong, X.; Kirkpatrick, R. J., Effects of the temperature and relative humidity on the structure of C-S-H gel. Cement and Concrete Research 1995, 25 (6), 1237-1245.

55. Merlino, S.; bonaccorsi, E.; Armbruster, T., Tobermorites: Their real structure and orderdisorder (OD) character. American Mineralogist 1999, 84, 1613-1621.

56. Grangeon, S.; Claret, F.; Roosz, C.; Sato, T.; Gaboreau, S.; Linard, Y., Structure of nanocrystalline calcium silicate hydrates: insights from X-ray diffraction, synchrotron $\mathrm{X}$-ray absorption and nuclear magnetic resonance. J. Appl. Crystallogr. 2016, 49 (3), 771-783.

57. Tambach, T. J.; Bolhuis, P. G.; Hensen, E. J. M.; Smit, B., Hysteresis in Clay Swelling Induced by Hydrogen Bonding: Accurate Prediction of Swelling States. Langmuir 2006, 22 (3), 1223-1234.

58. Ferrage, E.; Lanson, B.; Michot, L. J.; Robert, J. L., Hydration Properties and Interlayer Organization of Water and lons in Synthetic Na-Smectite with Tetrahedral Layer Charge. Part 1. Results from X-ray Diffraction Profile Modeling. Journal of Physical Chemistry C 2010, 114 (10), 4515 4526.

59. Eypert-Blaison, C.; Michot, L. J.; Humbert, B.; Pelletier, M.; Villieras, F.; de la Caillerie, J. B. D., Hydration water and swelling behavior of magadiite. $\mathrm{The} \mathrm{H}+\mathrm{Na}+, \mathrm{K}+, \mathrm{Mg} 2+$, and $\mathrm{Ca} 2+$ exchanged forms. Journal of Physical Chemistry B 2002, 106 (3), 730-742. 
60. Tournassat, C.; Appelo, C. A. J., Modelling approaches for anion-exclusion in compacted Nabentonite. Geochimica Et Cosmochimica Acta 2011, 75 (13), 3698-3710.

61. Ferrage, E.; Lanson, B.; Sakharov, B. A.; Drits, V. A., Investigation of smectite hydration properties by modeling experimental X-ray diffraction patterns: Part I. Montmorillonite hydration properties. American Mineralogist 2005, 90 (8-9), 1358-1374. 
For Table of Contents Use Only

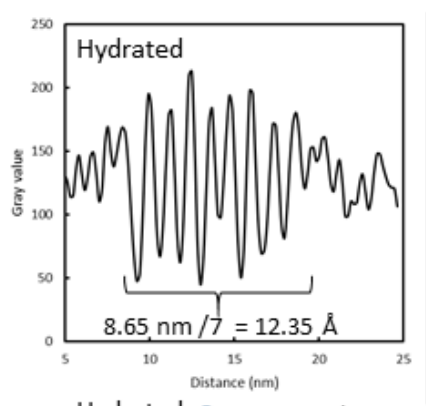

Hydrated - Water $\bullet$ Calcium

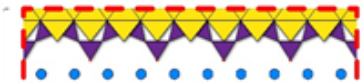
(N) AMAMAM $123 \AA$ । $\bullet \bullet \bullet \bullet \bullet \bullet$ L. $12-1$ Dried

$11 \mathrm{~A}$

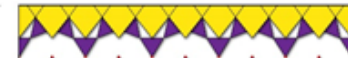

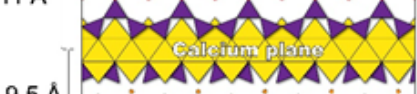
9.5 A

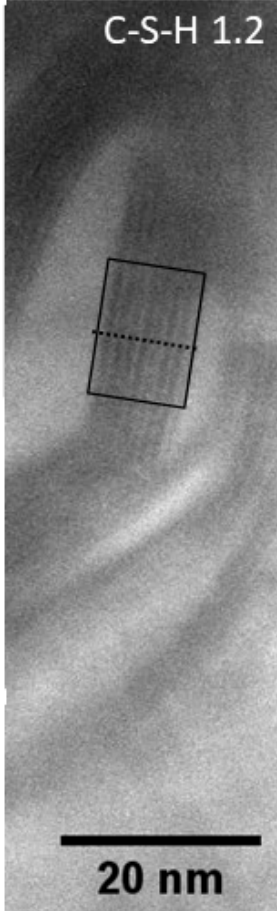

